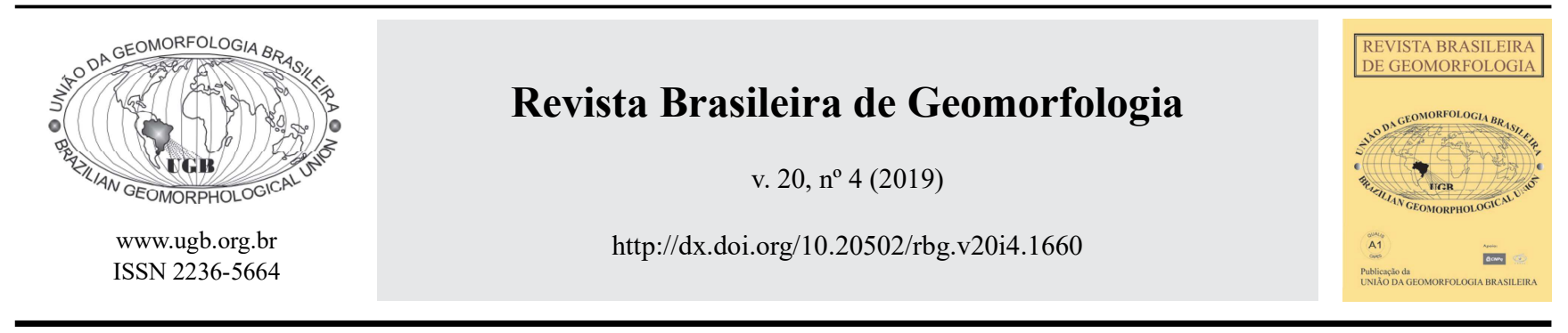

\title{
SIGNIFICADO DE DEPÓSITOS ALUVIAIS HOLOCÊNICOS EM AMBIENTE SEMIÁRIDO: ESTUDO DE CASO NA DEPRESSÃO SERTANEJA DA BAHIA
}

\author{
HOLOCENE ALLUVIAL DEPOSITS MEANING IN A SEMI-ARID \\ ENVIRONMENT: A CASE STUDY ON SERTANEJA DEPRESSION \\ (BAHIA STATE/BRAZIL)
}

\author{
Kleber Carvalho Lima \\ Departamento de Geografia, Universidade Estadual "Júlio Mesquita Filho" \\ Av. 24 - A, 1515, Rio Claro, São Paulo. CEP: 13506-900. Brasil \\ ORCID: 0000-0002-9468-2473 \\ E-mail: klebercarvalho.two@gmail.com \\ Cenira Maria Lupinacci \\ Departamento de Planejamento Territorial e Geoprocessamento, Universidade Estadual "Júlio Mesquita Filho" \\ Av. 24 - A, 1515, Rio Claro, São Paulo. CEP: 13506-900. Brasil \\ ORCID: 0000-0002-4732-1421 \\ E-mail: cenira.lupinacci@unesp.br
}

\begin{tabular}{l} 
Informações sobre o Artigo \\
\hline Recebido (Received): \\
22/06/2019 \\
Aceito (Accepted): \\
26/08/2019
\end{tabular}

\section{Palavras-chave:}

Geomorfologia Fluvial;

Planícies Aluviais; Fluxos

Efêmeros; Holoceno; Loe.

\section{Keywords:}

Fluvial Geomorphology; Floodplains; Ephemeral Flows; Holocene; Osl Dating.

\section{Resumo:}

Bacias de drenagem efêmeras e os seus depósitos aluviais, podem apresentar características que contribuem para o entendimento das dinâmicas climáticas ocorridas em escala de tempo do Holoceno. Embora sejam amplamente estudados em contextos semiáridos de diferentes países, no Brasil, o seu significado paleoclimático ainda é pouco conhecido. Nessa pesquisa, objetivou-se analisar as características de depósitos aluviais em duas bacias de drenagem de pequena dimensão areal, situadas no semiárido meridional, setor centro-norte da Depressão Sertaneja no Estado da Bahia, e compreender o seu significado à luz de condições climáticas holocênicas. Para isso, realizou-se o mapeamento geomorfológico de detalhe, a identificação de unidades aloestratigráficas, análise granulométrica e morfoscopia dos sedimentos, além da datação absoluta por Luminescência Opticamente Estimulada (LOE). Os depósitos aluviais apresentaram características associadas ao material litológico de origem cristalina e aos fluxos efêmeros, tais como [i] descontinuidade espacial ao longo do canal de drenagem; [ii] arquitetura deposicional indicativa de migração lateral e agradação do leito por fluxos laminares; [iii] predomínio de carga grosseira como cascalho e areia grossa, pobremente selecionada e; [iv] parâmetros estatísticos que sugerem a atuação de fluxos episódicos. Os eventos deposicionais ocorreram na transição Holoceno Médio - Holoceno Superior, entre 4.4 ka - 3.5 ka A.P. e entre 1.1 ka A.P. ao presente. Estes depósitos apresentam relações com condições climáticas secas estabelecidas nos últimos $4 \mathrm{ka}$, apontadas na literatura sobre este setor do semiárido brasileiro. 


\begin{abstract}
:
Ephemeral drainage basins and their alluvial deposits may have characteristics that contribute to the understanding of Holocene time-scale climate dynamics. Although widely studied in semiarid contexts of different countries, their paleoclimatic significance is still poorly understood in Brazil. In this research, we analyzed the characteristics of alluvial deposits in two small drainage basins, located in the southern semi-arid, central-north sector of the Sertaneja Depression - State of Bahia/Brazil. Our purpose also included interpreting the Holocene climatic conditions that contributed to the processes of alluvial deposit formation. We performed the geomorphological mapping, allostratigraphic layers identification on field trip, Particle Size Distribution (PSD) analysis, sediment morphology analysis, and Optically Stimulated Luminescence (OSL) dating. Alluvial deposits showed characteristics associated with crystalline rocks and ephemeral streams such as [i] spatial discontinuity along the drainage channel; [ii] depositional architecture indicative of bedding lateral migration and laminar flows; [iii] predominance of gravel and coarse sand, poorly sorted and; [iv] statistical parameters that suggest past episodes flows. The depositional events occurred in the Middle Holocene - Upper Holocene transition, between $4.4 \mathrm{kyr}$ - $3.5 \mathrm{kyr}$ B.P. and between 1.1 kyr B.P. to the present. These deposits have relations with dry climatic conditions established in the last 4 kyr.
\end{abstract}

\section{Introdução}

Durante o Holoceno, o intervalo temporal entre fases secas e fases úmidas foi relativamente curto, com transições bruscas, verificadas em intervalos de séculos, décadas e até de um ano (FERREIRA, 2002; VILES E GOUDIE, 2003; MANN et al, 2009). Nos ambientes fluviais, as feições deposicionais podem conter registros importantes dessas fases e preservar assinaturas de paleoclima regional (MATMON et al, 2016). As sequências sedimentares indicam períodos deposicionais, alternados com períodos de incisão e erosão (SCHUMM, 1981), que podem estar relacionados às variações nas condições de umidade nos últimos $11 \mathrm{ka}$, em escala local, regional ou global. Contudo, as fases climáticas não deixarão registros nos sistemas fluviais se não houverem condições de preservação dos depósitos (FOREMAN E STRAUB, 2017).

Os ambientes secos são altamente sensíveis às variações climáticas (BULL, 1991; YAIR E KOSSOVSKY, 2002), sendo que os depósitos aluviais associados a regimes efêmeros fornecem indicadores de processos paleoclimáticos em escala de tempo muito recente (GRAF, 1988). Esses registros podem indicar o momento do último evento deposicional realizado pelo canal fluvial (PORAT et al, 2010; MATMON et al, 2016) e fornecer uma estimativa do tempo de elaboração da superfície (FAERSHTEIN et al, 2016).

No semiárido brasileiro, registros das variações ocorridas nas condições climáticas durante o Holoceno podem ser encontrados em depósitos aluviais de bacias hidrográficas de maior dimensão espacial (TAVARES, 2010; CORREAA, 2011), especialmente naquelas onde as cheias sazonais são significativas (SANTOS, 2015; LIMA, 2017). Nas bacias de menor dimensão espacial, por outro lado, os depósitos aluviais provavelmente apresentarão registros de eventos climáticos extremos, de curta duração, resultantes de inundações repentinas (GRAF, 1988; GOUDIE, 2013), típicas de ambientes áridos e semiáridos. Ainda assim, pequenas bacias atualmente efêmeras, em contextos litoestruturais e topográficos particulares, podem apresentar extensos terraços fluviais, como testemunhos da ocorrência de fases úmidas pretéritas (MÜTZENBERG, 2007; SAMPAIO, 2013).

Contudo, assinala-se que (i) pesquisas que demonstrem evidências das pulsações climáticas do Holoceno em depósitos aluviais de pequenas bacias efêmeras do semiárido brasileiro são escassas; (ii) a maior parte dessas bacias estão localizadas na depressão sertaneja, desenvolvida sobre litologias do embasamento cristalino e; (iii) as condições de preservação dos depósitos aluviais dependem dos condicionantes climáticos e estruturais atuais (BERTRAND et al, 2017), da intensidade dos fluxos hídricos no canal, especificamente quando da ocorrência de eventos de grande magnitude, e das atividades antrópicas desenvolvidas nos fundos de vale. Diante disso, destaca-se a necessidade de compreensão da organização espacial e das propriedades dos depósitos aluviais no contexto de bacias de drenagem com essas características, bem como a contextualização desses depósitos no cenário de condições climáticas pretéritas. Ainda, faz-se necessário relacionar os atributos dos depósitos aluviais com possíveis variações entre fases secas e úmidas, ou fases mais secas que a atual, ocorridas durante o Holoceno. 
Dessa forma, o objetivo dessa pesquisa é analisar as características de depósitos aluviais e seu significado paleoclimático em pequenas bacias de drenagem efêmeras situadas no semiárido meridional brasileiro e estabelecer relações com condições climáticas pretéritas em escala regional, apontadas em pesquisas anteriores. Para isso, selecionaram-se as bacias de drenagem do riacho da Cruz e riacho da Várzea, posicionadas no setor centro-norte da Depressão Sertaneja no Estado da Bahia. Nessa porção, pesquisas geomorfológicas já vêm sendo desenvolvidas, com datação absoluta de depósitos aluviais em sítios relativamente próximos, permitindo possíveis correlações entre dados.

\section{Características regionais}

Na Bahia, a Depressão Sertaneja se desenvolveu entre o Planalto da Diamantina e os planaltos da borda leste (Figura 1), posicionados em altitudes superiores a 700 metros. No setor centro-norte da depressão, ocorrem superfícies de erosão, situadas entre 100 e 400 metros de altitude, e inselbergues que alcançam pouco mais de 600 metros de altitude (Figura 1). O clima dominante é semiárido, com temperatura média anual de $24^{\circ} \mathrm{C}$ (SEI, 1999) e isoietas que variam entre 500 e $700 \mathrm{~mm}$.

Nesse setor, a litologia é composta predominantemente por granitos, gnaisses, ortognaisses e sienitos datados do Arqueano e Proterozóico, agrupados no Bloco Serrinha e subdividido entre o Complexo Santaluz e o Greenstonebelt do Itapicuru (Figura 2). O trecho é caracterizado por falhas, lineamentos, eixos sinclinais e anticlinais associados aos domos granito-gnáissicos; e zonas de cisalhamento, cuja deformação litológica ocorreu durante o Proterozóico Inferior.

Os canais de drenagem, na maior parte dos casos, estabeleceram o seu leito sobre essas estruturas, aproveitando as zonas de fraqueza e as diferenças litológicas. São canais predominantemente efêmeros, contudo, ocorrem canais intermitentes, ambos afluentes diretos e indiretos do rio Itapicuru. O regime fluvial efêmero, em conjunto com a alta resistência do embasamento, favoreceu o desenvolvimento de depósitos aluviais quaternários, muitas vezes pouco expressivos, diretamente sobre as rochas do Arqueano e Proterozóico. Devido à natureza intermitente dos fluxos em canal, poucos depósitos encontram condições de preservação, podendo ser removidos à cada novo fluxo.

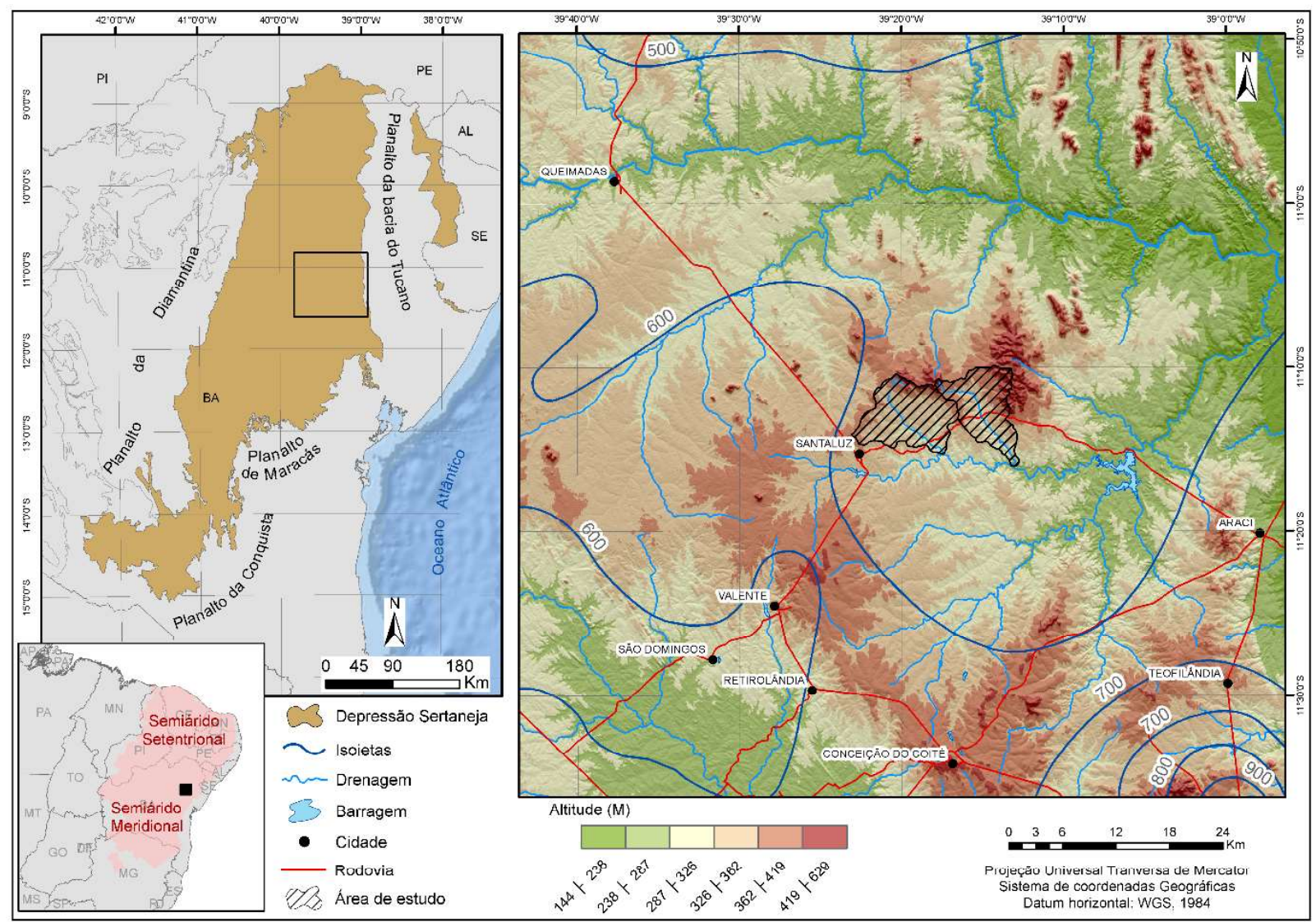

Figura 1 - Localização do setor centro-norte da Depressão Sertaneja no Estado da Bahia. 


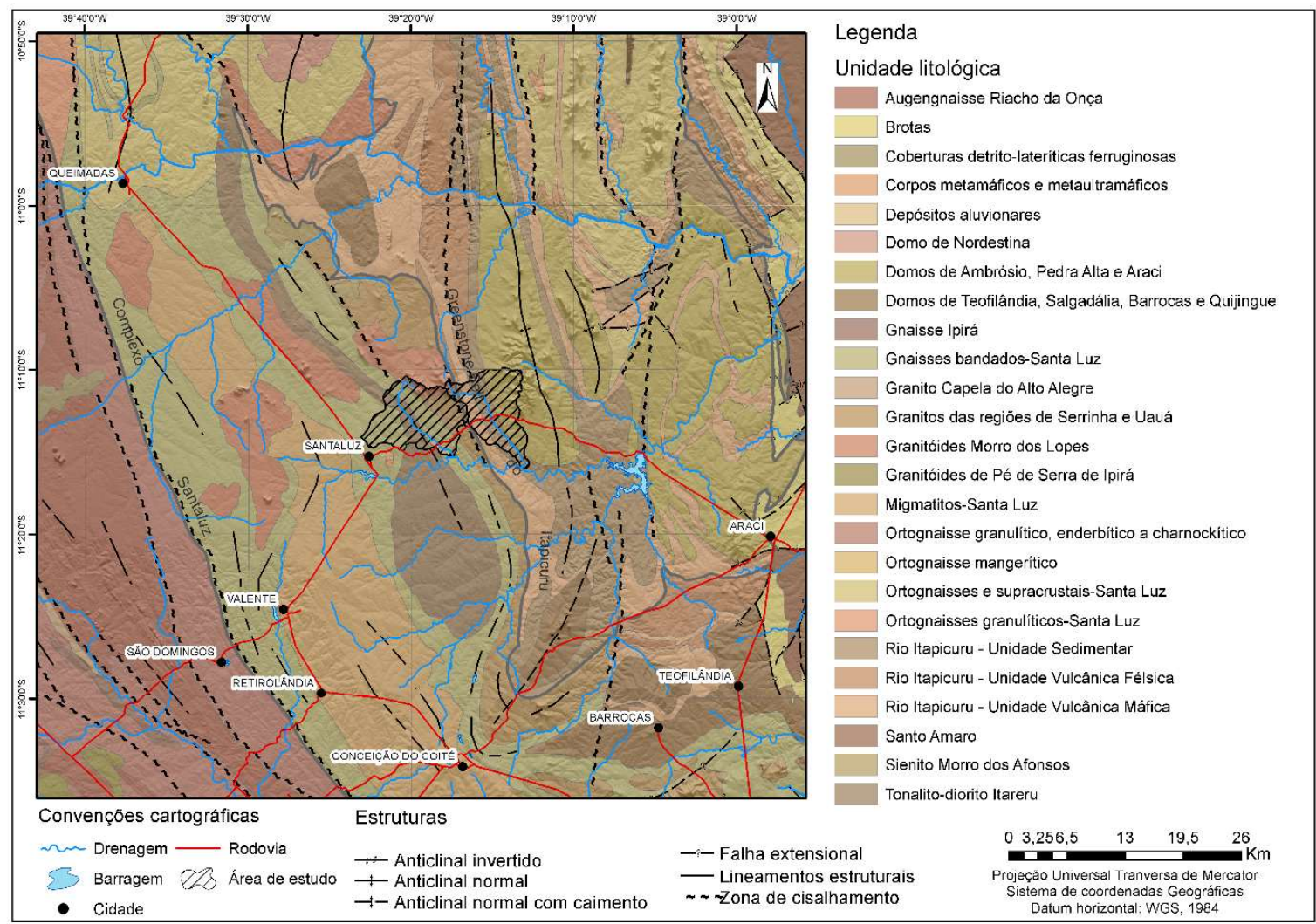

Figura 2 - Mapa geológico do setor centro-norte da Depressão Sertaneja no Estado da Bahia.

\section{Materiais e métodos}

\subsection{Seleção das áreas amostrais}

Duas bacias de drenagem foram selecionadas para esta pesquisa: a bacia do riacho da Cruz, com o canal principal e um dos seus afluentes, o riacho dos Ferreiros; e a bacia do riacho da Várzea. As bacias possuem o mesmo nível de base regional (rio Bom Sucesso) e drenam para o Oceano Atlântico, via rio Poço Grande e rio Itapicuru. Estas semelhanças podem salientar a atuação de processos morfológicos regionais em bacias de dimensão semelhante, porém, com litologias diferentes.

\subsubsection{Bacia do riacho da Cruz}

A bacia de drenagem do riacho da Cruz possui área de $65,9 \mathrm{~km}^{2}$, com altitudes que variam de 540 a $300 \mathrm{~m}$ e distância entre a sua nascente e a foz de $15,3 \mathrm{~km}$. Nós selecionamos o seu principal afluente, o riacho dos Ferreiros, para investigação dos seus depósitos, devido a expressividade de planícies aluviais ao longo do canal de drenagem. $\mathrm{O}$ riacho dos Ferreiros possui extensão de $9,12 \mathrm{~km}$, instalado sobre gnaisses e ortognaisses do Arqueano Médio Inferior e intrusões sieníticas do Proterozóico Inferior.

\subsubsection{Bacia do riacho da Várzea}

A bacia de drenagem do riacho da Várzea está posicionada entre um domo granito-gnáissico do Proterozóico Inferior, metabasaltos e metassedimentos do Greenstone Belt do Itapicuru, formados durante o Proterozóico Inferior. A bacia possui área de $54,3 \mathrm{~km}^{2} \mathrm{e}$ altitude entre 590 e $270 \mathrm{~m}$. A distância entre a nascente e a foz do curso principal é de $16,8 \mathrm{~km}$.

\subsection{Mapeamento geomorfológico}

Os mapas geomorfológicos (em anexo), foram elaborados em escala 1:40.000, com base em pares estereoscópicos de fotografias aéreas digitais do ano de 1974, disponibilizadas pela Companhia Baiana de Pesquisa Mineral (CBPM); além de imagens Digital Globe do an o de 2004 e 2016, disponíveis no banco de dados do software ArcGIS ${ }^{\circledR}$ e Google Earth ${ }^{\mathrm{TM}}$. Foram tomados pontos de controle nos trabalhos de campo, com o auxílio de aparelho GPS (Global Positioning System), para a calibragem do mapa.

O mapeamento serviu de base para a identificação das planícies aluviais e compreensão da sua 
distribuição espacial nas bacias de drenagem, além das suas relações com as demais formas. Foram utilizadas simbologias adaptadas de Tricart (1965); Verstappen e Zuidam (1975) e IBGE (2009), onde foram destacados os atributos do relevo e os processos envolvidos na sua elaboração. Os atributos priorizados foram a morfografia, morfometria, morfogênese, litologia, cronologia e hidrografia (GUSTAVSSON et al, 2006).

\subsection{Trabalho de campo}

As unidades aloestratigráficas foram identificadas a partir das características sedimentológicas, das descontinuidades e da altura relativa acima do canal de drenagem. O método aloestratigráfico é considerado o mais adequado para a identificação e interpretação de eventos deposicionais quaternários (SUGUIO, 2010), onde cada unidade registra um episódio de sedimentação, separada de outra unidade por episódios de erosão ou de pedogênese (MIALL, 1996; MIALL 2011).

As áreas em estudo não são grandes produtoras de sedimentos, devido às suas características litológicas e climáticas. Devido a isso, a posição das unidades aloestratigráficas com relação a superfície e ao substrato litológico foi levada em consideração, no sentido de não serem obtidas amostras que ainda pudessem estar expostas a radiação solar. Seções estratigráficas foram abertas até o contato litológico e posteriormente foram medidas e descritas. Todas as unidades foram amostradas para análise granulométrica. Para datação absoluta, apenas as unidades com profundidades que pudessem apresentar resultados confiáveis foram amostradas.

\subsection{Datação por LOE}

A datação por Luminescência Opticamente Estimulada (LOE) é um dos métodos mais utilizados em pesquisas sobre o Quaternário (SALLUN et al, 2007), por basear-se na luminescência de minerais abundantes na superficie terrestre, como o quartzo e o feldspato (CORRÊA et al, 2016), e por abranger uma escala temporal de cerca de $10^{6}$.anos. Devido a abundância desses minerais em sedimentos aluviais, a técnica é considerada como uma das mais adequadas para a datação desse tipo de material (STOKES, 1999; WALLINGA, 2002; TOOTH, 2015), justificando a escolha pelo uso da técnica nessa pesquisa.

No riacho da Várzea, as seções alcançaram $1 \mathrm{~m}$ de profundidade até o contato com o embasamento. As amostras foram tomadas a $80 \mathrm{~cm}$ de profundidade em unidade aloestratigráfica com continuidade lateral. No riacho da Cruz e riacho dos Ferreiros, as seções apresentaram profundidade de 90 e $60 \mathrm{~cm}$, respectivamente, sendo que as amostras foram tomadas a $50 \mathrm{~cm}$, em unidades isoladas. Amostras para datação foram coletadas com tubos de PVC de $40 \mathrm{~cm}$ de extensão e $5 \mathrm{~cm}$ de diâmetro, enterrados horizontalmente nas unidades aloestratigráficas. Para evitar qualquer exposição dos sedimentos à luz, os tubos foram imediatamente tampados com caps e colocados em sacos pretos opacos à prova de luz.

A preparação das amostras e as medições foram realizadas em ambiente de luz vermelha no Laboratório Datação, Comércio e Prestação de Serviços Ltda., com sede na cidade de São Paulo (SP/Brasil), de acordo com procedimentos laboratoriais de rotina (DATAÇÃO, 2018). O material da parte central dos tubos foi extraído e passou por tratamentos químicos e separação de 20 a 50 grãos de quartzo $(100-300 \mu \mathrm{m})$ isentos de matéria orgânica e metais pesados, com o objetivo de eliminar possíveis sinais residuais.

Parte do material foi submetida à radiação solar para decaimento dos isótopos de urânio (U), tório (Th) e potássio (K) (Tabela 1). Posteriormente, obteve-se a curva de calibração (MURRAY E ROBERTS, 1998) por meio das amostras irradiadas com as doses pré-definidas (Gy). Os valores das paleodoses foram alcançados pelo método Single Aliquot Regenerative-dose - SAR (MURRAY E WINTLE, 2000; WINTLE E MURRAY, 2006) com aplicação de 15 alíquotas para a aquisição do valor médio das doses equivalentes (DE). As idades absolutas foram obtidas através da relação entre a paleodose e a dose anual.

A precisão da dose equivalente foi verificada com o objetivo de se identificar idades com valores superestimados. Clarke (1996) e Clarke et al (1999) estipularam que amostras com bom grau de zeramento devem apresentar desvio padrão $\left(\sigma_{n-1)}\right.$ da média de $\mathrm{ED}<5 \mathrm{~Gy}$ e parâmetro de branqueamento $\left(\mathrm{S}_{\mathrm{N}}\right)<0.1$, onde $\mathrm{SN}=\left(\sigma_{n-}\right.$ , $(\chi)$. Amostras com valores acima do apresentado podem não ter sido expostas a radiação por tempo suficiente para zerar o valor acumulado durante à sua deposição e apresentam idades superestimadas. Adicionalmente, a precisão das idades foi avaliada por meio do valor de erro de cada amostra. Valores equivalentes a cerca de $5-10 \%$ da idade central da amostra apresentam $68 \%$ de chances (erro em $1 \sigma$ ) de estarem dentro do intervalo de erro apresentado (TOOTH, 2015). 
Tabela 1: Concentração de isótopos radioativos ${ }^{232} \mathbf{T h},{ }^{238} \mathbf{U}+{ }^{235} \mathrm{U},{ }^{40} \mathrm{~K}$ e teor de umidade.

\begin{tabular}{c|c|c|c|c|c}
\hline Cód. Lab. & Sítio & Th (ppm) & U (ppm) & K (\%) & Água (\%) \\
\hline 5084 & Riacho da Cruz & $5,680 \pm 0,332$ & $1,148 \pm 0,129$ & $3,207 \pm 0,241$ & 1,0 \\
5085 & Riacho dos Ferreiros & $3,273 \pm 0,217$ & $0,850 \pm 0,098$ & $3,016 \pm 0,191$ & 0,3 \\
5086 & Riacho da Várzea & $4,552 \pm 0,271$ & $1,149 \pm 0,115$ & $5,476 \pm 0,249$ & 1,1 \\
5087 & Riacho da Várzea & $4,409 \pm 0,269$ & $1,158 \pm 0,114$ & $4,640 \pm 0,236$ & 1,6 \\
\hline
\end{tabular}

\subsection{Análise granulométrica}

A análise granulométrica foi realizada no Laboratório para Análise de Formações Superficiais (LAFS) da UNESP/Rio Claro, por meio do método da Pipeta - IAC (CAMARGO et al, 2009). Esse é considerado um método manual eficaz para o reconhecimento de sedimentos finos, sendo que, o seu emprego em amostras com predomínio de material grosseiro permite a quantificação da classe silte e argila, mesmo que apresentem valores muito baixos.

A rotina de tratamento das amostras foi realizada de acordo com os protocolos operacionais padrão do LAFS. Foram reconhecidas as frações cascalho fino $(>4000 \mu \mathrm{m})$, cascalho muito fino $(4000 \mu \mathrm{m})$, areia muito grossa $(2000 \mu \mathrm{m})$, areia grossa $(1000 \mu \mathrm{m})$, areia média $(500 \mu \mathrm{m})$, areia fina $(250 \mu \mathrm{m})$, areia muito fina $(125 \mu \mathrm{m})$, silte $(63 \mu \mathrm{m})$ e argila $(2 \mu \mathrm{m})$. Observa-se que os nódulos de areia e material fino, com alto grau de coesão, foram contabilizados como fração $>4000$ $\mu \mathrm{m}$, pois preservaram essa característica, mesmo após serem submetidos ao destorroamento em gral e pistilo de porcelana de alta resistência.

Sequencialmente foi realizada a análise estatística pelo método gráfico (FOLK E WARD, 1957) no Gradistat 6.0 (BLOTT E PYE, 2001), com o objetivo de identificar-se o grau de seleção, assimetria e curtose. Esses parâmetros foram incorporados devido à alta probabilidade de mistura de sedimentos aluviais com sedimentos oriundos dos pedimentos por escoamento superficial. Além disso, foram analisados o grau de esfericidade, arredondamento e textura superficial (fosca ou brilhante), segundo Pettijohn et al. (1987), da fração areia média em lupa estereoscópica binocular, com o objetivo de compreender-se o tipo de transporte ao qual os sedimentos foram submetidos.

\section{Resultados}

4.1 Espacialização dos depósitos aluviais e aloestratigrafia

\subsubsection{Sítio riacho da Cruz}

Planícies aluviais no riacho da Cruz ocorrem em maior quantidade a montante da barragem riacho da Cruz, ao longo do canal principal e em parte dos seus afluentes (Figura 3a). São planícies espacialmente descontínuas com aspecto de bolsões de sedimentação. Apresentam larguras inferiores a 90 metros e extensão que varia entre 10 metros e 1 quilômetro. Nos trechos com planície aluvial, os canais de drenagem geralmente são desconfinados e, em alguns trechos, apresentam descontinuidades.

A jusante da barragem, a planície aluvial (Figura $3 b)$ se estende por um trecho de 2 quilômetros até à sua confluência com o rio Bom Sucesso e alcança largura de 180 metros. Em parte desse trecho, o canal principal apresenta padrão anastomosado com desenvolvimento de vegetação entre os canais. Nos últimos 430 metros (Figura 3c), antes da confluência com o rio Bom Sucesso, o riacho da Cruz possui padrão sinuoso com a formação de um terraço fluvial (Figura 3d) a 1 metro de altura em relação ao canal. A seção representativa apresentou profundidade de $90 \mathrm{~cm}$ e cinco unidades aloestratigráficas (Figura 3e) com predomínio de fração areia (Tabela 2), exceto as unidades 1 e 2c, onde predominou a fração $>4000 \mu \mathrm{m}$, em detrimento dos baixos percentuais de finos.

\subsubsection{Sítio riacho dos Ferreiros}

Ao longo do riacho dos Ferreiros, as planícies aluviais apresentam descontinuidade espacial com aspecto de bolsões de sedimentação (Figura 4a). São pequenas planícies com larguras inferiores a 170 metros e extensão 
inferior a 1,6 quilômetros. O canal de drenagem apresenta leito alternadamente confinado e desconfinado e padrão de drenagem sinuoso. Próximo à confluência com o riacho da Cruz, o canal apresenta trecho desconfinado com o desenvolvimento de um leque de desague sobre a planície do riacho da Cruz (Figura 4b).

Cerca de 600 metros a montante (Figura 4c) da sua confluência com o riacho da Cruz, foram identi- ficadas à margem do canal atual (Figura 4d), cinco unidades aloestratigráficas plano paralelas (Figura 4e) com sedimentos pouco consolidados com elevados percentuais de areia, especialmente areia grossa, e pouca participação de sedimentos finos (Tabela 3). A unidade aloestratigráfica 1 apresentou características granulométricas semelhantes à unidade 1 da seção do riacho da Cruz, com elevado percentual da fração $>4000 \mu \mathrm{m}$.
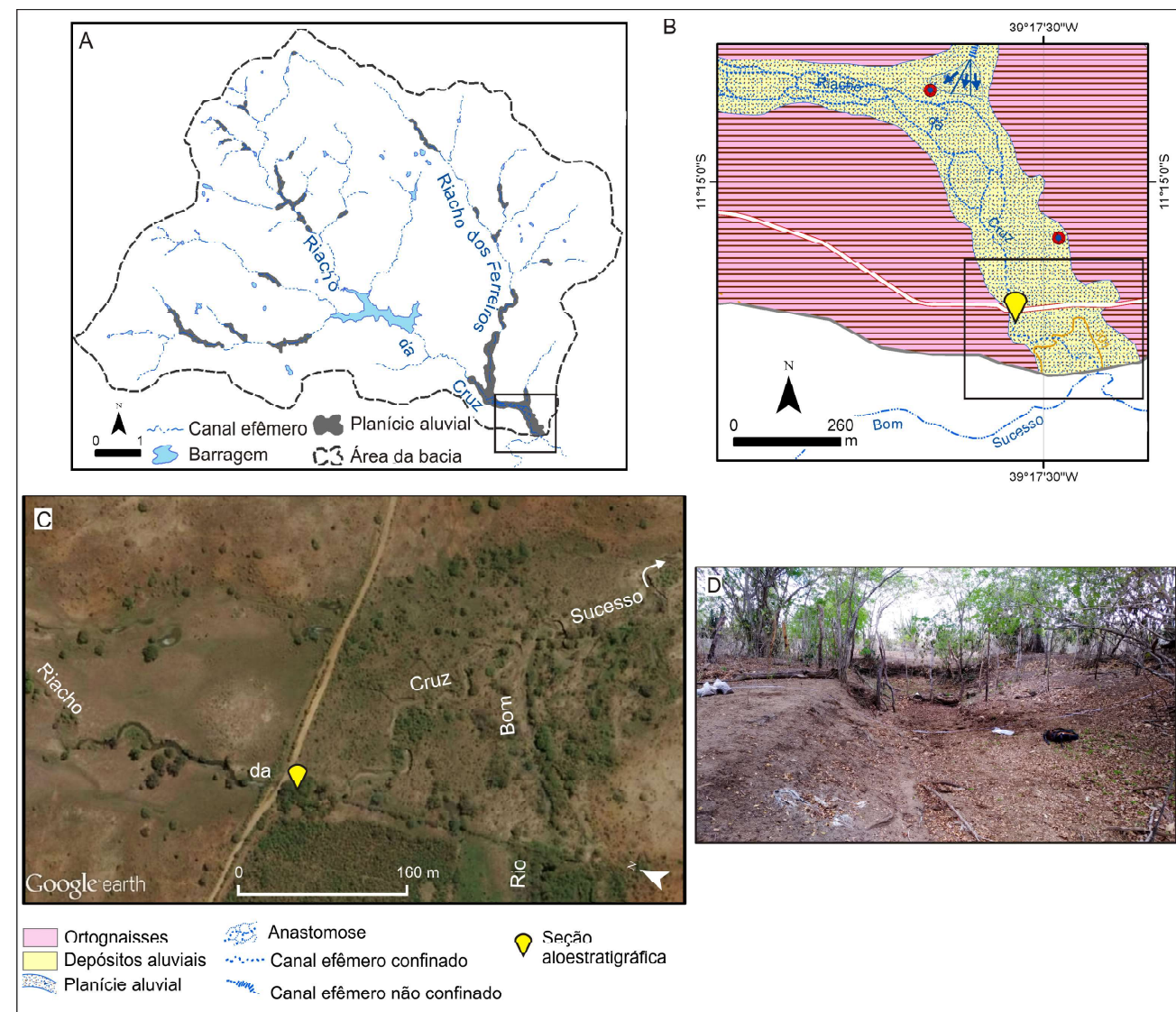

E

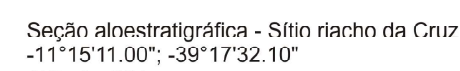
Altitude: $301 \mathrm{~m}$
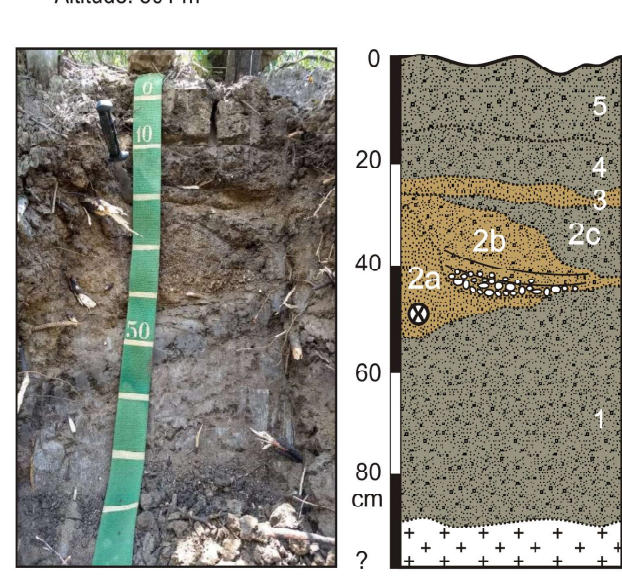

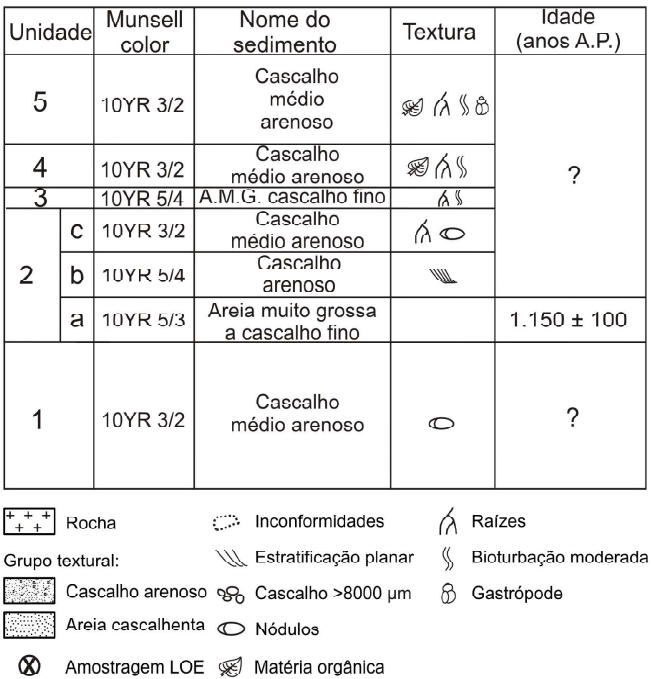

Figura 3 - a. Distribuição das planícies aluviais na bacia de drenagem; b. trecho final do riacho da Cruz com anastomoses; c. padrão sinuoso do canal principal e posicionamento da seção aloestratigráfica; d. terraço posicionado em sinuosidade do canal; e. descrição das unidades aloestratigráficas. 
Lima K. C. \& Lupinacci C. M.

Tabela 2 : Distribuição das partículas nas unidades aloestratigráficas do riacho da Cruz.

\begin{tabular}{|c|c|c|c|c|c|c|c|c|c|c|c|}
\hline \multirow[b]{2}{*}{$\begin{array}{l}\text { Unidade } \\
\text { aloestrat. }\end{array}$} & \multirow[b]{2}{*}{$\begin{array}{l}\text { Altitude } \\
\text { (m) }\end{array}$} & \multirow[b]{2}{*}{$\begin{array}{l}\text { Prof. } \\
\text { (m) }\end{array}$} & \multicolumn{2}{|c|}{ Cascalho (\%) } & \multicolumn{5}{|c|}{ Areia (\%) } & \multicolumn{2}{|c|}{ Lama $(\%)$} \\
\hline & & & Fino & $\begin{array}{l}\text { Muito } \\
\text { fino }\end{array}$ & $\begin{array}{l}\text { Muito } \\
\text { grossa }\end{array}$ & Grossa & Média & Fina & $\begin{array}{l}\text { Muito } \\
\text { fina }\end{array}$ & Silte & Argila \\
\hline \multicolumn{12}{|c|}{ Sítio riacho da Cruz } \\
\hline 5 & 301 & 0.1 & 37.00 & 9.95 & 0.98 & 3.46 & 18.82 & 20.92 & 7.61 & 1.06 & 0.19 \\
\hline 4 & & 0.2 & 27.09 & 13.07 & 1.03 & 7.85 & 21.36 & 19.67 & 8.51 & 1.15 & 0.28 \\
\hline 3 & & 0,3 & 1,59 & 11,13 & 10,97 & 40,02 & 25,10 & 6,88 & 3,82 & 0.40 & 0,09 \\
\hline $2 \mathrm{c}$ & & 0.4 & 68,20 & 7,14 & 1.01 & 0.99 & 9.00 & 10,82 & 2,01 & 0.69 & 0,14 \\
\hline $2 \mathrm{~b}$ & & 0.4 & 12.00 & 29.29 & 12,89 & 29.09 & 10.86 & 4.35 & 1,08 & 0.35 & 0.10 \\
\hline $2 \mathrm{a}$ & & 0.5 & 2.80 & 13.27 & 6.53 & 33.73 & 26.35 & 13.43 & 3.30 & 0.48 & 0.12 \\
\hline 1 & & 0.7 & 70.27 & 6,54 & 0.03 & 1,65 & 7,63 & 10.74 & 2.78 & 0,26 & 0,11 \\
\hline
\end{tabular}
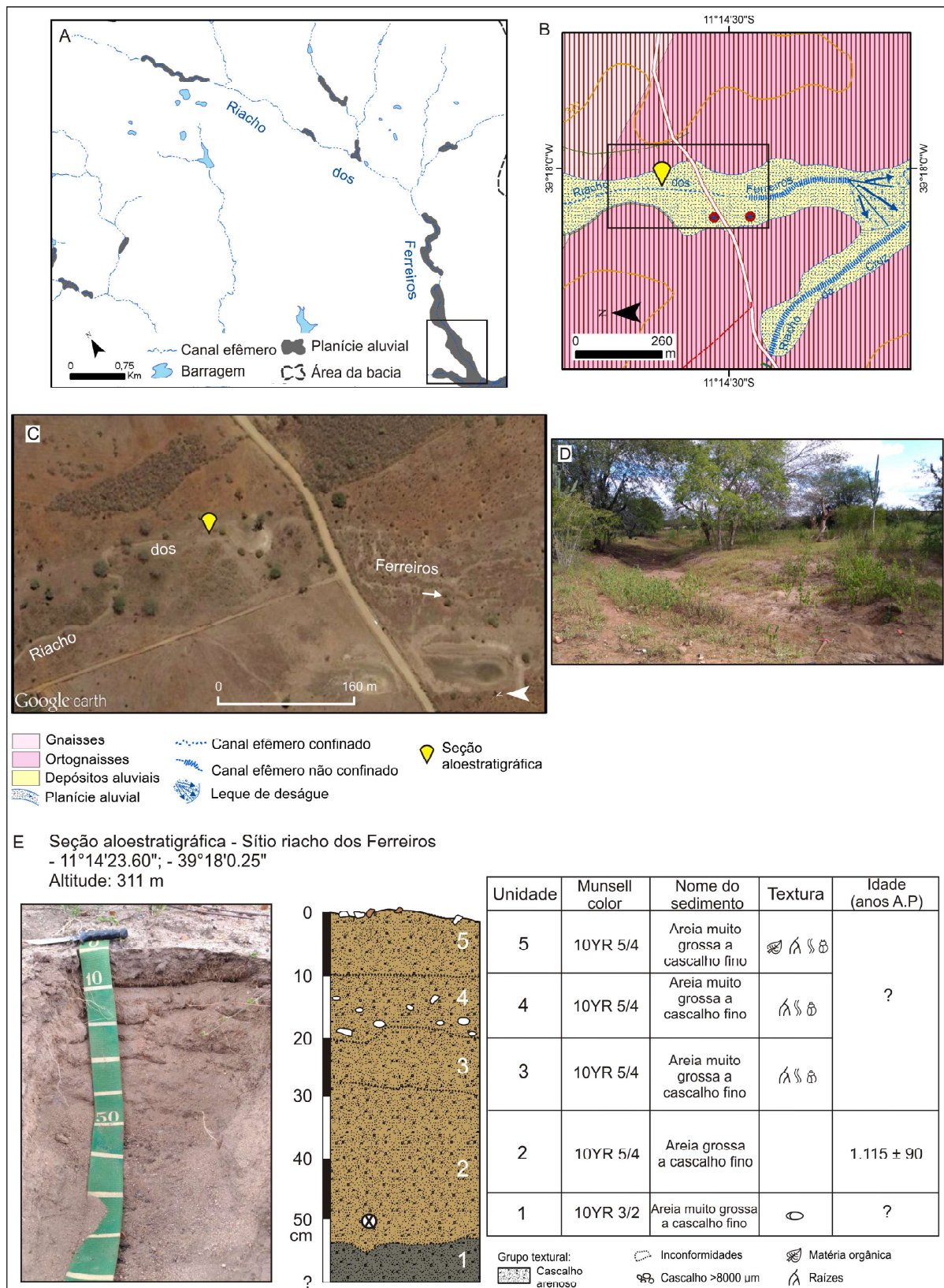

ro confinado

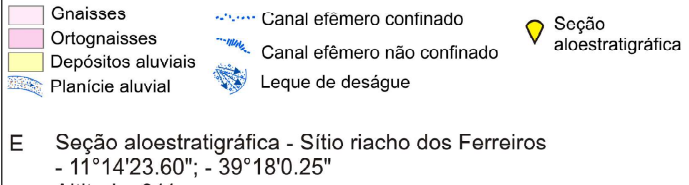

$\nabla$ Seção

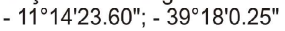

\begin{tabular}{|c|c|c|c|c|c|}
\hline \multirow{3}{*}{$\begin{array}{r}0 \\
10\end{array}$} & Unidade & $\begin{array}{c}\text { Munsell } \\
\text { color }\end{array}$ & $\begin{array}{l}\text { Nome do } \\
\text { sedimento }\end{array}$ & Textura & $\begin{array}{c}\text { Idade } \\
\text { (anos A.P) }\end{array}$ \\
\hline & 5 & 10YR 5/4 & $\begin{array}{l}\text { Areia muito } \\
\text { grossa a } \\
\text { Cascallıu fino }\end{array}$ & 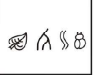 & \multirow{3}{*}{ ? } \\
\hline & 4 & 10YR 5/4 & $\begin{array}{l}\text { Areia muito } \\
\text { grossa a } \\
\text { cascalho fino }\end{array}$ & IÂS & \\
\hline 30 & 3 & 10YR 5/4 & $\begin{array}{l}\text { Areia muito } \\
\text { grossa a } \\
\text { cascalho fino }\end{array}$ & (A⿱亠⿻⿰丿亅八阝 & \\
\hline 40 & 2 & 10YR 5/4 & $\begin{array}{c}\text { Areia grossa } \\
\text { a cascalho fino }\end{array}$ & & $1.115 \pm 90$ \\
\hline \multirow{2}{*}{$\begin{array}{l}50 \\
\mathrm{~cm}\end{array}$} & 1 & 10YR $3 / 2$ & $\begin{array}{l}\text { Areia muito grossa } \\
\text { a cascalho fino }\end{array}$ & 0 & $?$ \\
\hline & \multicolumn{2}{|c|}{ 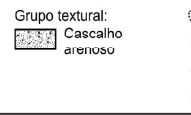 } & $\begin{array}{l}\text { Inconformidades } \\
\text { Cascalho >8000 } \mu \mathrm{m} \\
\text { Nódulos } \\
\text { Alllustrayem LOE }\end{array}$ & \multicolumn{2}{|c|}{ 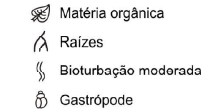 } \\
\hline
\end{tabular}

Figura 4 - a. Distribuição espacial das planícies aluviais no riacho dos Ferreiros; b. trecho final da planície aluvial; c. trecho com localização da seção aloestratigráfica; d. depósitos aluviais à margem do canal; e. descrição das unidades aloestratigráficas. 
Tabela 3: Distribuição das partículas nas unidades aloestratigráficas do riacho dos Ferreiros.

\begin{tabular}{|c|c|c|c|c|c|c|c|c|c|c|c|}
\hline \multirow[b]{2}{*}{$\begin{array}{l}\text { Unidade } \\
\text { aloestrat. }\end{array}$} & \multirow[b]{2}{*}{$\begin{array}{l}\text { Altitude } \\
\text { (m) }\end{array}$} & \multirow[b]{2}{*}{$\begin{array}{l}\text { Prof. } \\
\text { (m) }\end{array}$} & \multicolumn{2}{|c|}{ Cascalho (\%) } & \multicolumn{5}{|c|}{ Areia $(\%)$} & \multicolumn{2}{|c|}{ Lama (\%) } \\
\hline & & & Fino & $\begin{array}{l}\text { Muito } \\
\text { fino }\end{array}$ & $\begin{array}{l}\text { Muito } \\
\text { grossa }\end{array}$ & Grossa & Média & Fina & $\begin{array}{l}\text { Muito } \\
\text { fina }\end{array}$ & Silte & Argila \\
\hline \multicolumn{12}{|c|}{ Sítio riacho dos Ferreiros } \\
\hline 5 & 311 & 0,1 & 5,28 & 6,86 & 4,32 & 42.70 & 27,04 & 8.24 & 4.48 & 0,89 & 0,19 \\
\hline 4 & & 0.2 & 2.61 & 11.05 & 11.38 & 40.05 & 26.13 & 6.79 & 1.53 & 0.38 & 0.08 \\
\hline 3 & & 0.3 & 4,19 & 9.11 & 5.41 & 40.61 & 33,04 & 6.67 & 0.73 & 0.14 & 0.09 \\
\hline 2 & & 0.4 & 3.91 & 9.42 & 4,28 & 29.50 & 33.28 & 15.01 & 3.99 & 0.47 & 0.13 \\
\hline 1 & & 0,6 & 66,96 & 5,40 & 2,67 & 1,04 & 8,32 & 12,84 & 2,52 & 0,12 & 0,13 \\
\hline
\end{tabular}

\subsubsection{Sítio riacho da Várzea}

No riacho da Várzea, planícies aluviais ocorrem restritamente no canal principal, espacialmente distribuídas em dois trechos (Figura 5a). O trecho a montante do açude Várzea da Pedra possui largura aproximada de 60 metros e cerca de 1,6 quilômetros de extensão. Na porção situada a jusante da barragem, a planície apresenta aspecto alongado, com largura média de 80 metros e aproximadamente 3,7 quilômetros. O canal de drenagem apresenta trechos alternadamente confinados e desconfinados (Figura 5b). Nos trechos confinados, o padrão é sinuoso. Em um trecho da planície aluvial (figs. 5c; 5d), situado a 1,3 quilômetros da confluência com o rio Bom Sucesso, nós identificamos duas unidades aloestratigráficas (Figura 5e) com continuidade lateral, disposição planar e transição gradual entre uma unidade e outra. Predominou a classe areia fina (Tabela 4) com percentuais pouco significativos de argila, bem como de sedimentos $>4000 \mu \mathrm{m}$.

\subsection{Granulometria e morfoscopia dos sedimentos}

Em todas as amostras as partículas de areia corresponderam a mais de $70 \%$ do material (tabela 5). $\mathrm{Na}$ análise comparativa, as amostras do riacho da Várzea apresentaram percentuais maiores de sedimentos finos (silte e argila), enquanto que as amostras do riacho da Cruz e riacho dos Ferreiros apresentaram percentuais mais significativos de cascalho. Todas as amostras foram classificadas como polimodais, com mais de uma moda, onde diferentes classes granulométricas foram muito frequentes (tabela 5). Esse comportamento pode ser visualizado por meio de gráficos de distribuição das partículas (Figura 6a; 6b). A classificação textural variou entre areia ligeiramente cascalhenta e areia cascalhenta (Figura $6 \mathrm{c}$ ).

De maneira geral, predominaram grãos com esfericidade baixa e grau de arredondamento entre muito anguloso, anguloso e subanguloso (figura 7). Também, predominaram grãos com textura superficial brilhosa, indicando polimento suave causado por transporte em meio hídrico. Nas amostras referentes ao riacho da Várzea, a frequência de grãos com esfericidade alta e arredondamento angulosos a subanguloso foi maior (Figura 7a) que nos demais sítios, coexistindo com grãos de esfericidade baixa, muito angulosos e angulosos (Figura 7b). Nos riachos da Cruz e dos Ferreiros, o predomínio absoluto de grãos com baixa esfericidade, muito angulosos a subangulosos (Figura 7c e 7d), sugeriu que estes sedimentos foram menos trabalhados que os sedimentos do riacho da Várzea.

\subsection{Idades LOE}

A intensidade da luminescência emitida permitiu o cálculo do último momento em que os grãos receberam radiação solar, onde as amostras apresentaram idades posicionadas no Holoceno Superior (Tabela 6). Considerando-se o erro das idades centrais, a amostra 5087 (Tabela 6) está posicionada na transição Holoceno Médio - Holoceno Superior. Correlações entre as idades, altitude e profundidade de amostragem indicaram uma sequência lógica do tempo de soterramento das unidades. As amostras com idades próximas apresentaram valores semelhantes de paleodose indicando a confiabilidade do resultado.

Nas quatro amostras, o erro das idades apresentou valores abaixo de $9 \%$ da idade central, atestando a adequabilidade do intervalo de tempo obtido em $1 \sigma$ (TOOTH, 2015). Como as amostras apresentaram idades recentes, não foi necessário calcular o parâmetro de branqueamento $\left(\mathrm{S}_{\mathrm{N}}\right)$. Segundo Clarke (1996), esse é um parâmetro adicional, utilizado conjuntamente com o desvio padrão da média de ED, para identificação de idades superestimadas de amostras mais antigas. $\mathrm{O}$ desvio padrão das amostras apresentou valores com alto grau de precisão, situados abaixo de $2 \mathrm{G}_{\mathrm{y}}$, demonstrando um bom zeramento do sinal de LOE durante a deposição, antes do soterramento. 


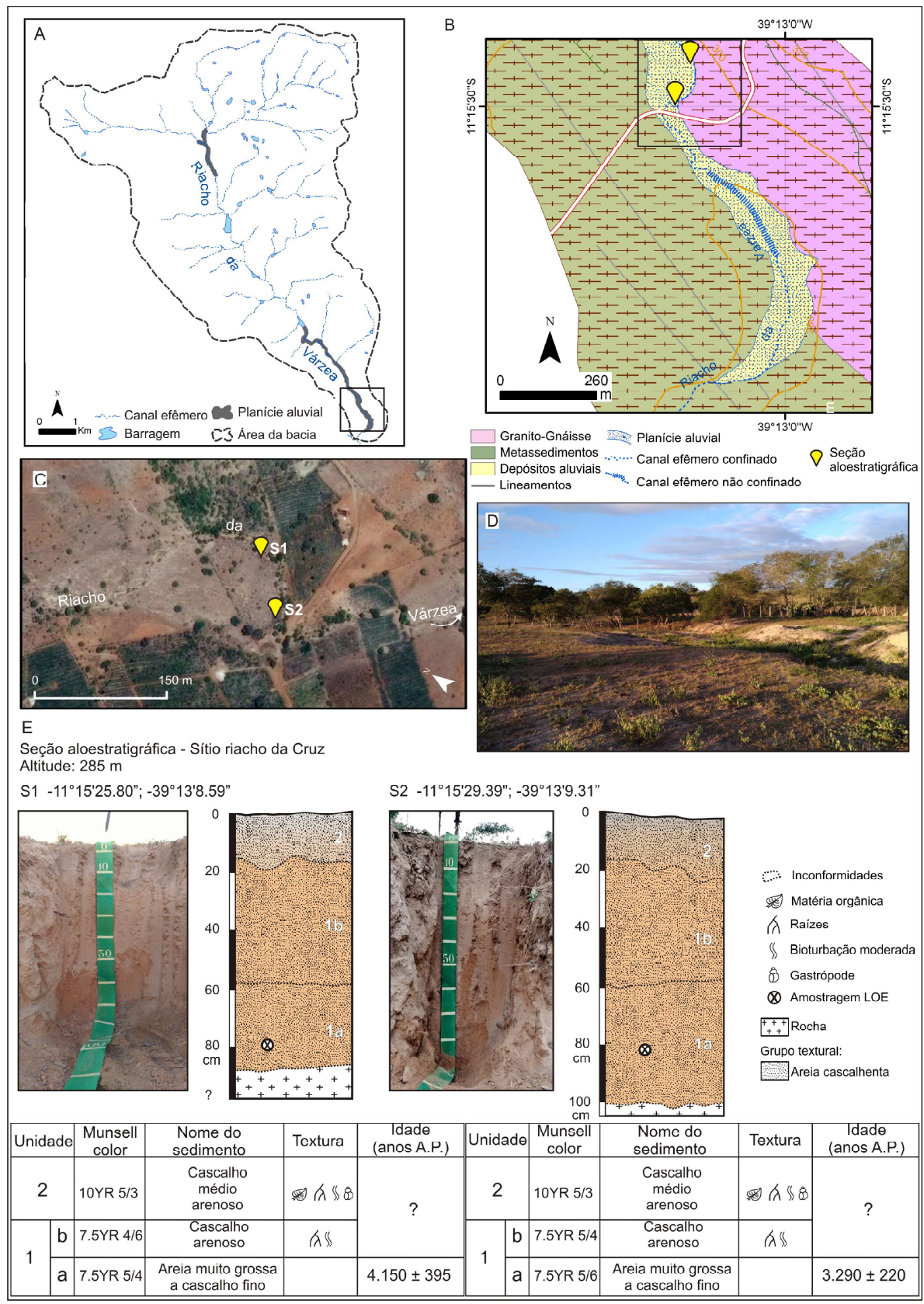

Figura 5 - a. Distribuição das planícies aluviais do riacho da Várzea; b. trecho do canal em leito confinado e desconfinado; c. posicionamento das seções aloestratigráficas; $d$. planície aluvial no trecho amostrado; e. descrição das unidades.

Tabela 4: Distribuição das partículas das unidades aloestratigráficas do riacho da Várzea.

\begin{tabular}{|c|c|c|c|c|c|c|c|c|c|c|c|}
\hline \multirow[b]{2}{*}{$\begin{array}{l}\text { Unidade } \\
\text { aloestrat. }\end{array}$} & \multirow[b]{2}{*}{$\begin{array}{l}\text { Altitude } \\
\text { (m) }\end{array}$} & \multirow[b]{2}{*}{$\begin{array}{l}\text { Prof. } \\
\text { (m) }\end{array}$} & \multicolumn{2}{|c|}{ Cascalho (\%) } & \multicolumn{5}{|c|}{ Areia $(\%)$} & \multicolumn{2}{|c|}{ Lama $(\%)$} \\
\hline & & & Fino & $\begin{array}{c}\text { Muito } \\
\text { fino }\end{array}$ & $\begin{array}{l}\text { Muito } \\
\text { grossa }\end{array}$ & Grossa & Média & Fina & $\begin{array}{l}\text { Muito } \\
\text { fina }\end{array}$ & Silte & Argila \\
\hline \multicolumn{12}{|c|}{ Sítio riacho da Várzea (S1) } \\
\hline 2 & 285 & 0,1 & 0,00 & 1.47 & 2,60 & 19,52 & 25,58 & 29,80 & 18,04 & 2,95 & 0,03 \\
\hline $1 \mathrm{~b}$ & & 0.4 & 0.13 & 3.48 & 2.97 & 18.13 & 24.78 & 29.31 & 18.17 & 3.00 & 0.04 \\
\hline $1 \mathrm{a}$ & & 0,8 & 0,0 & 1.53 & 1,83 & 14,58 & 22.32 & 32.65 & 23.34 & 3,68 & 0.07 \\
\hline \multicolumn{12}{|c|}{ Sítio riacho da Várzea (S2) } \\
\hline 2 & 285 & 0,1 & 1.41 & 2.99 & 2.77 & 15.85 & 22.70 & 29.49 & 21.54 & 3.23 & 0.03 \\
\hline $1 \mathrm{~b}$ & & 0,4 & 0.0 & 3,76 & 2.52 & 15,67 & 26,34 & 30,42 & 18,29 & 2,95 & 0,05 \\
\hline $1 \mathrm{a}$ & & 0,8 & 0,0 & 2.89 & 2.18 & 15.66 & 25,03 & 30,71 & 20.40 & 3,05 & 0,08 \\
\hline
\end{tabular}


Significado de Depósitos Aluviais Holocênicos em Ambiente Semiárido: Estudo de Caso

Tabela 5: Distribuição das partículas e parâmetros morfométricos das unidades aloestratigráficas datadas.

\begin{tabular}{|c|c|c|c|c|c|c|c|c|c|c|c|c|c|c|}
\hline \multirow{2}{*}{$\begin{array}{l}\text { Unidade } \\
\text { aloestrat. }\end{array}$} & \multirow{2}{*}{$\begin{array}{l}\text { Altit. } \\
(\mathrm{m})\end{array}$} & \multirow{2}{*}{$\begin{array}{l}\text { Prof. } \\
\text { (m) }\end{array}$} & \multicolumn{2}{|c|}{ Cascalho $(\%)$} & \multicolumn{5}{|c|}{ Areia $(\%)$} & \multicolumn{2}{|c|}{$\operatorname{Lama}(\%)$} & \multirow[b]{2}{*}{$\begin{array}{l}\text { Grau de } \\
\text { seleção }\end{array}$} & \multirow[b]{2}{*}{ Assimetria } & \multirow[b]{2}{*}{ Curtose } \\
\hline & & & Fino & $\begin{array}{l}\text { Muito } \\
\text { fino }\end{array}$ & $\begin{array}{l}\text { Muito } \\
\text { grossa }\end{array}$ & Grossa & Média & Fina & $\begin{array}{l}\text { Muito } \\
\text { fina }\end{array}$ & Silte & Argila & & & \\
\hline \multicolumn{15}{|c|}{ Sítio riacho da Várzea } \\
\hline $\begin{array}{l}1 \mathrm{a} \\
\text { (S1) }\end{array}$ & 285 & 0,8 & 0,0 & 1,53 & 1,83 & 14,58 & 22,32 & $\begin{array}{c}32,6 \\
5\end{array}$ & 23,34 & 3,68 & 0,07 & \multirow{2}{*}{$\begin{array}{l}\text { Pobremente } \\
\text { selecionada } \\
\text { Pobremente } \\
\text { selecionada }\end{array}$} & Grosseira & Platicúrtica \\
\hline $1_{(\mathrm{S} 2)}$ & 285 & 0,8 & 0,0 & 2,89 & 2,18 & 15,66 & 25,03 & $\begin{array}{c}30,7 \\
1 \\
\end{array}$ & 20,40 & 3,05 & 0,08 & & Grosseira & Leptocúrtica \\
\hline \multicolumn{15}{|c|}{ Sítio riacho da Cruz } \\
\hline $2 \mathrm{a}$ & 301 & 0,5 & 2,80 & 13,27 & 6,53 & 33,73 & 26,35 & $\begin{array}{c}13,4 \\
3\end{array}$ & 3,30 & 0,48 & 0,12 & $\begin{array}{l}\text { Pobremente } \\
\text { selecionada }\end{array}$ & Simétrica & Leptocúrtica \\
\hline \multicolumn{15}{|c|}{ Sítio riacho dos Ferreiros } \\
\hline 2 & 311 & 0,5 & 3,91 & 9,42 & 4,28 & 29,50 & 33,28 & $\begin{array}{c}15,0 \\
1\end{array}$ & 3,99 & 0,47 & 0,13 & $\begin{array}{l}\text { Pobremente } \\
\text { selecionada }\end{array}$ & Grosseira & Leptocúrtica \\
\hline
\end{tabular}

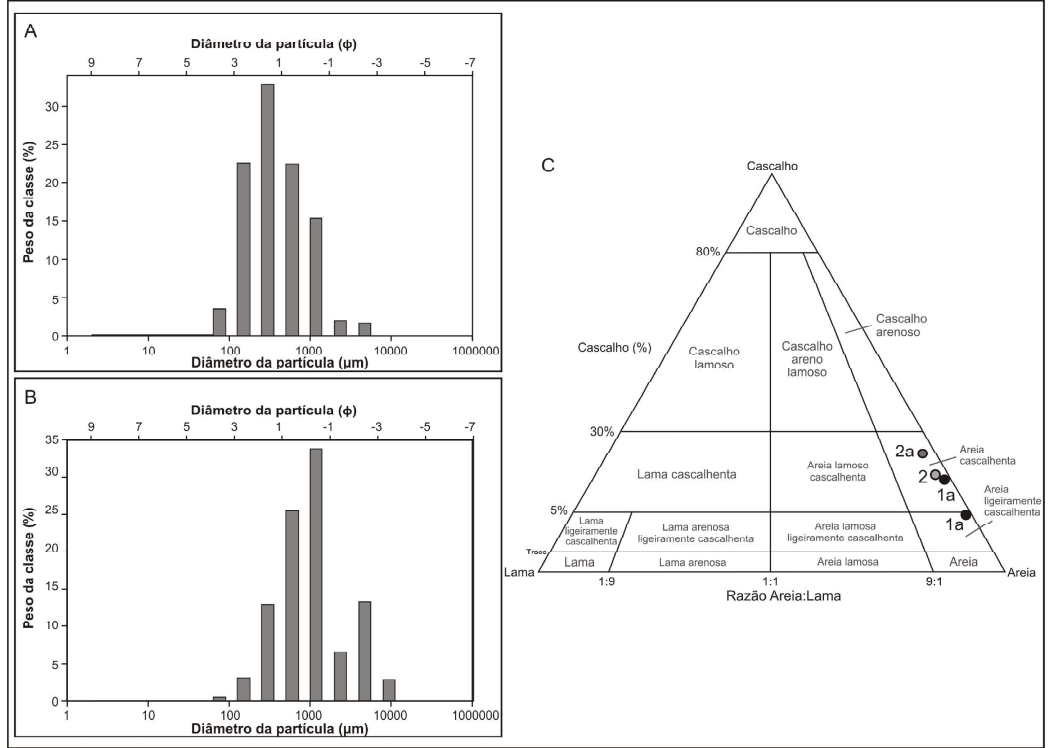

Figura 6 - Exemplos de distribuição das partículas por tamanho de grão com: A. curva platicúrtica (unidade 1a - riacho da Várzea); B. curva leptocúrtica (unidade 2 - riacho dos Ferreiros). C. Diagrama ternário com as classes texturais das amostras.

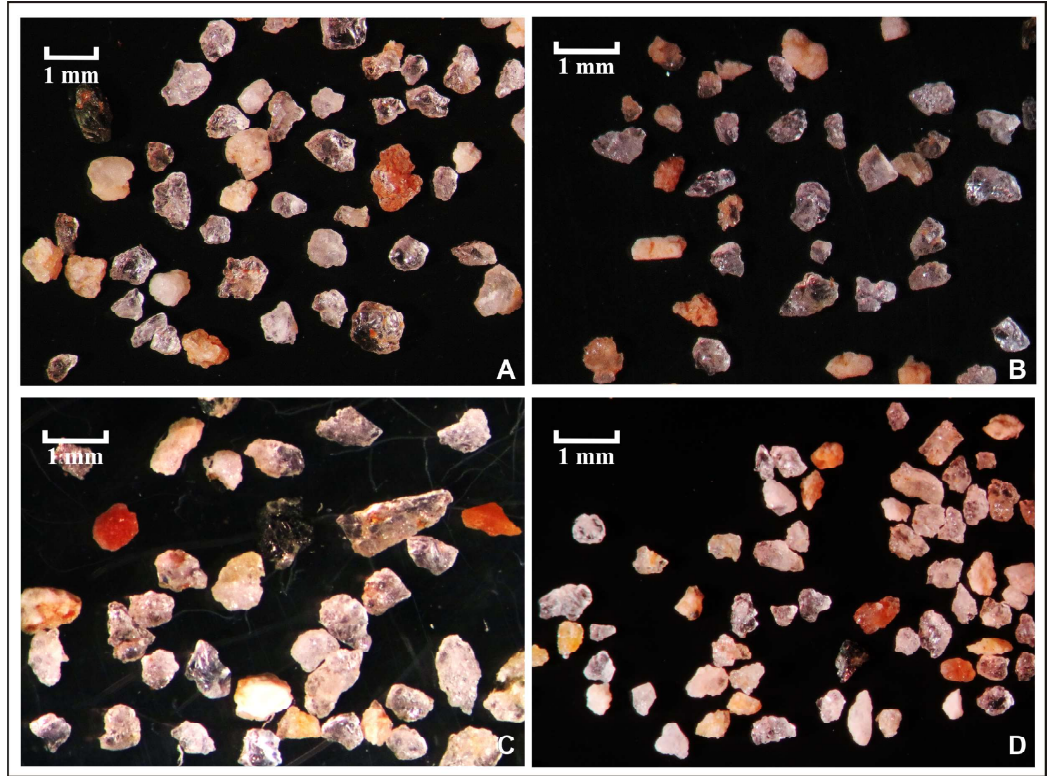

Figura 7 - Fotomicrografias de grãos da fração areia média, correspondentes às unidades aloestratigráficas do riacho da Várzea (A e B); riacho da Cruz (C); e riacho dos Ferreiros (D). 
Tabela 6: Idades absolutas das unidades aloestratigráficas, onde $\mathbf{P}$ (paleodose) é o valor médio das doses equivalentes (DE) e $\sigma_{n-1}$ corresponde ao desvio padrão de cada DE com relação a $P$.

\begin{tabular}{|c|c|c|c|c|c|c|c|}
\hline $\begin{array}{l}\text { Cód. } \\
\text { Lab. }\end{array}$ & Sítio & $\begin{array}{l}\text { Alt. } \\
\text { (m) }\end{array}$ & $\begin{array}{l}\text { Prof. } \\
(\mathrm{cm})\end{array}$ & $\begin{array}{c}\text { Dose anual } \\
(\mu \mathrm{Gy} / \mathrm{ano})\end{array}$ & $P\left(G_{y}\right)$ & $\sigma_{n-1}$ & Idade (anos A.P.) \\
\hline 5084 & Riacho da Cruz & 301 & 50 & $3.890 \pm 200$ & 4,5 & 0,3 & $1.150 \pm 100$ \\
\hline 5085 & $\begin{array}{l}\text { Riacho dos } \\
\text { Ferreiros }\end{array}$ & 311 & 50 & $3.480 \pm 160$ & 3,9 & 0,3 & $1.115 \pm 90$ \\
\hline 5086 & Riacho da Várzea & 285 & 80 & $5.930 \pm 200$ & 19,5 & 1,1 & $3.290 \pm 220$ \\
\hline 5087 & Riacho da Várzea & 285 & 80 & $5.120 \pm 195$ & 21,2 & 1,8 & $4.150 \pm 395$ \\
\hline
\end{tabular}

\section{Discussão}

\subsection{Interpretação das planícies aluviais e unidades aloestratigráficas}

A distribuição espacial das planícies aluviais ao longo do riacho da Cruz, riacho dos Ferreiros e riacho da Várzea possui relação direta com os fluxos em pulsos, caracterizados pelo rápido aumento na descarga até atingirem o pico, seguido pelo seu declínio (REID E FROSTICK, 1997; THORNES, 2009). Ao diminuírem a velocidade, os fluxos cessam e depositam a carga sedimentar nas áreas adjacentes ao canal (GRAF, 1988). Contudo, a depender da magnitude da descarga, a deposição ocorrerá apenas no próprio leito do canal. Silva (1986) e Correa (2011) afirmaram que o padrão descontínuo das planícies aluviais é comum no semiárido brasileiro, especificamente na Depressão Sertaneja. Nessas regiões, ocorre a migração do canal de drenagem à cada evento que gera fluxo (THORNES, 2009). Por outro lado, considera-se que, em contextos específicos do semiárido, a exemplo do riacho Grande (Paraíba), as áreas de sedimentação em fundo de vale apresentam forte controle estrutural, imprimindo o caráter descontínuo das planícies aluviais e migração dos canais de drenagem (BARROS et al., 2017).

As características granulométricas das unidades aloestratigráficas refletiram aspectos da dinâmica de canais efêmeros, onde o comportamento polimodal pode ser explicado pela própria dinâmica sedimentar regional (FRIEDMAN, 1961). As amostras foram classificadas como pobremente selecionadas, o que é esperado para areias de origem fluvial (FRIEDMAN, 1967), devido a elevada dispersão dos grãos com relação a tendência central. A curtose platicúrtica é típica de ambientes fluviais (ALVES, 1999), porém três das amostras apresentaram curtose leptocúrticas, devido ao comportamento polimodal da curva de distribuição dos grãos. A assimetria negativa, ou grosseira, apresentada pelas amostras, contradiz o ambiente deposicional fluvial, quando o esperado é assimetria positiva, devido ao fluxo de transporte unidirecional (FRIEDMAN, 1961; FRIEDMAN, 1967).

Todavia, acredita-se que a descontinuidade do fluxo hídrico no canal de drenagem seja responsável pelo comportamento da curtose e assimetria, uma vez que predominaram, grau de arredondamento e esfericidade, típicos de sedimentos pouco trabalhados pelo escoamento fluvial. No contexto dos riachos da Cruz e dos Ferreiros, os grãos analisados sugerem que os sedimentos foram pouco trabalhados, possivelmente introduzidos mais recentemente no ambiente fluvial, em comparação com os sedimentos do riacho da Várzea. A idade absoluta do material corroborou com essa hipótese. No contexto do riacho da Várzea, a presença de grãos com esfericidade alta e grau de arredondamento entre anguloso e subanguloso, pode indicar, de maneira mais clara, a mistura de material oriundo de áreas fonte a montante, com sedimentos transportados pelo escoamento superficial nos pedimentos adjacentes ao depósito.

A arquitetura deposicional nas seções analisadas permitiu a distinção entre processos fluviais, sob a mesma condição climática. A unidade aloestratigráfica 2 da seção do riacho da Cruz, apresentou subunidades suavemente côncavas, sobrepostas entre si, que sugerem processos de migração lateral do canal (FRIEND, 1983; GIBLING, 2006), cuja variação granulométrica pode indicar energias de fluxo diferentes. Seguindo essa possibilidade, a migração lateral do canal teria ocorrido por volta de 1.15 ka A.P., seguida da incisão e formação do terraço. Supõe-se que, após a incisão do canal, ocorreram contribuições de material que soterraram a subunidade 2, oriundas de fluxos em canal (unidade 3) e/ou de contribuições do escoamento superficial nos pedimentos adjacentes ao terraço (unidades 4 e 5 ).

No riacho dos Ferreiros, a seção aloestratigráfica 
apresenta elementos arquiteturais relacionados a deposição por fluxos laminares de baixa velocidade, comuns em leitos planos fracamente confinados (NORTH E TAYLOR, 1996), com carga sedimentar grosseira, ocorrida por volta de 1.11 ka A.P. Do ponto de vista topográfico, as idades obtidas no riacho dos Ferreiros e no riacho da Cruz são correlacionáveis quanto a diferença altimétrica entre os topos das seções: 311 e 301 $\mathrm{m}$, respectivamente. Acredita-se que a incisão ocorrida na foz do riacho da Cruz não tenha remontado aos seus afluentes, no caso, o riacho dos Ferreiros que, por sua vez, teria experimentado o entulhamento do fundo de vale. Condição que perdura até os dias atuais, cujas evidências estão presentes nos trechos não confinados do canal e no leque de desague, situados próximos à seção aloestratigráfica (ver figuras. 4b e 4c).

No riacho da Várzea, a arquitetura deposicional das seções apresentam características de deposição por fluxos laminares de carga de leito, com geometria plana. A continuidade lateral sugere uma condição de estabilidade do canal com relação à migração lateral, podendo, nesse caso estar associado aos lineamentos estruturais, transversais ao canal de drenagem no seu trecho final, que contribuíram para a retenção de sedimentos no trecho amostrado (ver Figura 5b). Isso permite afirmar que a variável estrutural se constituiu como elemento que condicionou características distintas entre os depósitos. Do ponto de vista cronológico, as idades obtidas no riacho da Várzea são compatíveis com as idades obtidas nos riachos da Cruz e dos Ferreiros, visto que estão posicionadas em altitude inferior e apresentaram idades de soterramento mais antigas, entre o Holoceno Médio e o Holoceno Superior.

\subsection{Contexto paleoclimático regional}

Correlações entre condições paleoclimáticas holocênicas no contexto do semiárido brasileiro ainda são limitadas devido à sua grande dimensão espacial, frente às pesquisas realizadas na região até o momento. Contudo, acredita-se que é possível estabelecer aproximações entre os dados dessa pesquisa e as investigações realizadas anteriormente no setor meridional (Figura 8). Dessas pesquisas, utilizaram-se as idades absolutas correspondentes ao período de tempo compreendido pelas idades obtidas nas áreas em estudo.

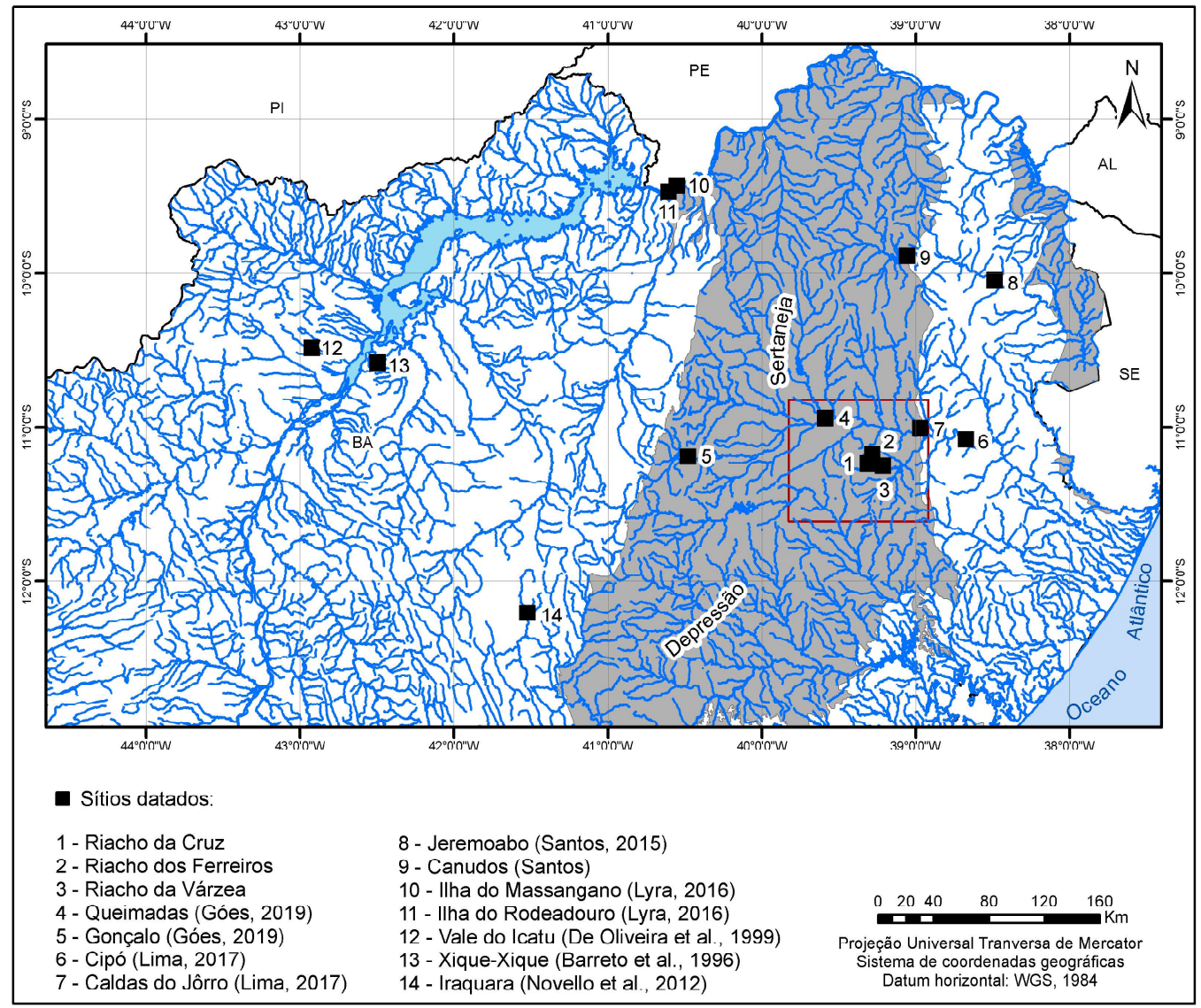

Figura 8 - Distribuição espacial de sítios geomorfológicos no setor meridional, com idades correspondentes ao Holoceno. 
Barreto et al. (1996) pesquisaram o campo de dunas inativas do médio rio São Francisco e, por meio de análise de sedimentos e datações por termoluminescência (TL), reconheceram três episódios de formação das dunas entre o Holoceno e o Pleistoceno, sendo o último posicionado entre $4 \mathrm{ka}-0.9 \mathrm{ka}$ A.P. A principal conclusão dos autores é que de 4 ka até o presente, houve o aumento da atividade eólica e das condições de aridez, seguidos da expansão da vegetação de Caatinga e Cerrado sobre as dunas. Segundo os autores, o aumento da aridez durante o Holoceno Tardio pode ser atribuído a eventos de longa duração, vinculados a atuação do El-Niño. No vale do Icatu, médio rio São Francisco, De Oliveira et al. (1999) realizaram datações por TL e por ${ }^{14} \mathrm{C}$ em depósitos de turfas e identificaram cinco zonas produtoras de pólen, sendo uma delas posicionada entre $4.5 \mathrm{ka} \mathrm{e}$ o presente. Segundo os autores, essa zona atestou condições paleoambientais de semiaridez que perduram até o presente, após sucessivas fases, ora mais úmidas, ora secas, conduzidas por atuação de El-Niño Oscilação Sul (ENOS) e da Zona de Convergência Intertropical (ZCIT).

Do ponto de vista climático, a área em estudo apresenta correlação temporal com os campos de dunas pois, os processos morfogenéticos atuantes nas duas áreas, foram conduzidos por condições de semiaridez durante o Holoceno Superior até o presente. Porém, a intensidade com a qual as variáveis climáticas atuaram em ambas as áreas, provavelmente foram distintas, já que a ZCIT, por exemplo, atua de maneira mais frequente nas áreas pesquisadas por Barreto et al. (1996) e Oliveira et al. (1999), ao contrário das bacias de drenagem estudadas.

Sob o aspecto das dinâmicas fluviais ocorridas durante o Holoceno, pesquisas desenvolvidas em rios de maior extensão no semiárido meridional, demonstraram a ocorrência de diferentes intensidades da energia do fluxo fluvial, associadas a fases e/ou pulsos climáticos secos e úmidos. No rio Vaza-Barris, Santos (2015) obteve idades através da LOE e ${ }^{14} \mathrm{C}$ entre 1.6 e $1.4 \mathrm{ka}$ para sedimentos aluviais grosseiros, em níveis de baixo terraço, situados no município de Jeremoabo e Pinhões. De acordo com o autor, esses sedimentos correspondem a momentos de semiaridez, impulsionados por atuações do El-Niño, intercalados por pulsos úmidos, registrados nas unidades com sedimentos argilosos, possivelmente depositados em cheias, quando da ocorrência de $L a$ -Niña.

No rio Itapicuru, Lima (2017) identificou ciclos de deposição fluvial holocênicos em níveis de baixo terraço por meio de análise granulométrica e datação por LOE. No município de Cipó, ciclos deposicionais associados a fases de deposição de carga grosseira, sob condições secas, obtiveram idades entre 1 e 0.9 ka. No município de Tucano, a idade do ciclo com sedimentos grosseiros foi de $3.7 \mathrm{ka}$. Também no rio Itapicuru, Góes (2019) identificou um ciclo grosseiro na localidade de Gonçalo, ocorrido entre 1.1 - $0.9 \mathrm{ka}$, correspondente ao mesmo ciclo identificado nos baixos terraços de Cipó; e em Queimadas, localidade mais próxima à nossa área de estudo, o autor obteve idade de 0.8 ka para o ciclo com deposição de sedimentos grosseiros.

Devido à dimensão espacial da área drenada pelos rios Vaza-Barris e Itapicuru, os seus depósitos possuem registros relativos a cheias sazonais (GRAF, 1988), ocorridas em escala de tempo do Holoceno, sob regime de fluxo intermitente. Embora apresentem dinâmicas fluviais distintas, com relação às drenagens analisadas (dadas a diferenças entre variáveis como área de drenagem, litologia, posição das nascentes em áreas de maior umidade, declividade do canal, dentre outras), os ciclos deposicionais grosseiros identificados nestes dois rios são correlacionáveis temporalmente com os depósitos grosseiros do riacho da Cruz e riacho da Várzea, conduzidos pela mesma condição climática seca, também identificada nos campos de dunas do São Francisco. Essa mesma condição seca, estabelecida nos últimos $4 \mathrm{ka}$, teria favorecido a deposição de carga grosseira nas ilhas fluviais Massangano e Rodeadouro, no rio São Francisco, entre Juazeiro e Petrolina. Segundo Lyra (2016), esses depósitos apresentaram idades LOE entre $1.1 \mathrm{ka}$ e 0.82 ka A.P., e comprovam a ocorrência de pulsos climáticos regionais ainda mais secos que os atuais, associados a Pequena Idade do Gelo (LIA - Little Ice Age) e a Anomalia Climática Medieval (MCA - Medieval Climate Anomaly), além da atuação de eventos severos de estiagem, vinculados ao El-Niño, por volta de $0.8 \mathrm{ka}$.

Novello et al. (2012) reconstruiu paleoprecipitações contínuas nos últimos $3 \mathrm{ka}$, com base em datações por ${ }^{230} \mathrm{Th}$ de isótopos de oxigênio $\left(\delta^{18} \mathrm{O}\right)$ em espeleotemas de cavernas, situadas em Iraquara, no Planalto da Diamantina. Os autores afirmaram que nesse período, o semiárido meridional foi marcado por uma condição geral seca, intercalado por eventos úmidos de curta duração. Contudo, o Planalto da Diamantina apresenta valores pluviométricos maiores devido ao fator orográ- 
fico (altitudes $>800$ metros). Dessa forma, considera-se tratar do mesmo momento seco observado nas demais áreas da região. No entanto, é possível que os pulsos úmidos não tenham ocorrido, ao menos com a mesma intensidade, nos setores da Depressão Sertaneja que englobam as bacias pesquisadas.

\section{Conclusões}

Com base nos dados e discussões apresentadas, sugere-se que a condição de semiaridez climática atual do setor meridional do semiárido brasileiro, se estabeleceu nos últimos $4 \mathrm{ka}$, abrangendo as áreas da Depressão Sertaneja. Porém, observa-se que variáveis topográficas, litológicas e estruturais distintas ocorrem na região, podendo causar diferentes respostas temporais e espaciais no relevo. Ainda assim, o cenário sugerido para as bacias do riacho da Cruz e da Várzea é condizente com as condições climáticas de semiaridez apontadas nas pesquisas anteriores, podendo ser generalizado para outras bacias de drenagem com dimensões areais e características ambientais semelhantes.

Os procedimentos metodológicos adotados permitiram a obtenção de dados confiáveis, sendo possível salientar que (i) a datação por LOE de depósitos aluviais, associados a drenagens efêmeras, é eficaz, desde que observadas, de forma criteriosa, as condições de preservação do material; (ii) assim como apontado na literatura, os depósitos analisados apresentaram indicadores de processos ocorridos em escala de tempo muito recente, sendo possível que resultados semelhantes sejam alcançados em outras áreas de contexto análogo; (iii) além da datação absoluta por luminescência, é necessário o emprego de outras técnicas, a exemplo das que foram desenvolvidas nessa pesquisa, no sentido de aproximar os eventos registrados nos depósitos, com condições pretéritas de clima.

O conjunto de dados apresentados nessa pesquisa constitui-se como a primeira aproximação entre paleoindicadores geomorfológicos, obtidos em bacias de drenagem efêmeras do semiárido meridional, e proxies paleoclimáticos regionais, correspondentes ao Holoceno Médio/Superior. Embora os dados apresentem correspondência geral com as pesquisas anteriores, no sentido de uma condição semiárida estabelecida regionalmente, as correlações ainda são imprecisas para se estabelecer um cenário evolutivo do relevo para esse setor. Ainda, enfatiza-se a necessidade de desenvolvimento de pesquisas dessa natureza em áreas com características semelhantes, com a experimentação de outras técnicas e paleoindicadores, com o propósito de se avaliar os efeitos das alternâncias ou pulsos climáticos sobre a dinâmica dos sistemas fluviais em ambientes semiáridos do Brasil.

\section{Agradecimentos}

À Coordenação de Aperfeiçoamento de Pessoal de Nível Superior (CAPES) pela concessão da bolsa de estágio pós-doutoral (processo n ${ }^{\circ} 88882.317847 / 2019$ $01)$; e ao Prof. Dr. Jémisson Mattos dos Santos e equipe do Laboratório da Dinâmica e Gestão do Ambiente Tropical (Geotrópicos), da Universidade Estadual de Feira de Santana, pelo suporte nos trabalhos de campo. Agradecemos ainda aos revisores anônimos pelas contribuições referentes ao manuscrito.

\section{Referências Bibliográficas}

ALVES, M.I.C. Análise dimensional de sedimentos fluviais: formação de Alvarães e Depósitos de terraços da bacia do rio Lima (NW de Portugal). Estudos do Quaternário, 2, 1999, p. 65-72. DOI: 10.30893/eq.v0i2.17

BARRETO, A.M.F. Interpretação paleoambiental do sistema de dunas fixadas do médio Rio São Francisco, Bahia. 1996. 174 p. Tese (Doutorado em Geologia) - Instituto de Geociências, Universidade de São Paulo, São Paulo, 1996.

BARROS, A.C.M. Controles estruturais sobre a sedimentação de fundos de vale na bacia do riacho Grande/PB. Clio Arqueológica, v. 32, n. 3, 2017, p. 1-36. DOI: 10.20891/clio. V32N3p1-36

BERTRAND, G.; HIRATA, R.; AULER, A.; CRUZ, F.; CARY, L.; PETELET-GIRAUD, E.; CHATTON, E.; AQUILINA, L.; MOQUET, J.S.; BUSTAMANTE, M.G.; MILlO, C.; MARTINS, V.; MONTENEGRO, S.; CELLE-JEANTON, H. Groundwater isotopic data as potential proxy for Holocene paleohydroclimatic and paleoecological models in NE Brazil. Paleogeography, Paleoclimatology, Paleoecology, 469, 2017 p. 92-103. DOI: 10.1016/j.palaeo.2017.01.004

BLOTT, S. J.; PYE, K. Gradistat: a grain size distribution and statistics package for the analysis of unconsolidated sediments. Earth Surface Processes and Landforms, 26, p. 1237-1248, 2001. DOI: $10.1002 /$ esp.261

BULL, W.B. Geomorphic responses to climatic change. New 
York: Oxford University Press, 1991. 326 p.

CAMARGO, O.A.; MONIZ, A.C.; JORGE, J.A.; VALADARES, J.M. Métodos de análise química, mineralógica e física de solos do Instituto Agronômico de Campinas. Campinas: Instituto Agronômico de Campinas, 1986. 94 p.

CLARKE, M.L. IRSL dating of sands: bleaching characteristics at deposition inferred from the use of single aliquots. Radiation Measurements, 26, p. 611-620, 1996. DOI: 10.1016/13504487(96)00004-2

CLARKE, M.L.; RENDELL, H.M.; WINTLE, A.G. Quality assurance in luminescence dating. Geomorphology, 29, p. 173185, 1999. DOI: 10.1016/S0169-555X(99)00013-6

CORRÊA, A. C. B. Antropogênese e morfogênese sob a ação de eventos climáticos de alta magnitude no semiárido pernambucano: o caso da Bacia do riacho Salgado. Revista Brasileira de Geomorfologia, v. 12, n.3, p.25-36, 2011. DOI: 10.20502/rbg.v12i0.256

CORRÊA, A. C. B.; TAVARES, B. A. C.; MONTEIRO, K. A.; FONSÊCA, D. N. A aplicação de técnicas geocronométricas em Geomorfologia: uma atualização metodológica. Espaço Aberto, v. 6, n.1, p. 45-74, 2016.

DATAÇÃO Comércio \& Prestação de Serviços LTDa. Metodologia de análise. São Paulo, 2018. Disponível em: http:// datacao.dominiotemporario.com/doc/Metodologia_de_Datacao. pdf. Acesso em: 10 junho 2018.

DE OLIVEIRA, P.E.; BARRETO, A.M.F.; SUGUIO, K. Late Pleistocene/Holocene climatic and vegetational history of the Brazilian caatinga: the fossil dunes of the middle São Francisco River. Paleogeography, Paleoclimatology, Paleoecology, 152, p. 319-337, 1999. DOI: 10.1016/S0031-0182(99)00061-9

FAERSHTEIN, G.; PORAT, N., AVNI, Y.; MATMON, A. Aggradation-incision transition in arid environments at the end of the Pleistocene: An example from the Negev Highlands, southern Israel. Geomorphology, 253, p. 289-304, 2016. DOI: 10.1016/j.geomorph.2015.10.017

FERREIRA, A. B. Variabilidade climática e dinâmica geomorfológica. Publicações da Associação Portuguesa de Geomorfólogos, v. 1, p. 7-15, 2002.

FOLK, R.L.; WARD, W.C. Brazos River bar: a study in the significance of grain size parameters. Journal of Sedimentary Petrology, 27, p. 3-26, 1957. DOI: 10.1306/74D70646-2B2111D7-8648000102C1865D

FOREMAN, B.Z.; STRAUB, K.M. Autogenic geomorphic processes determine the resolution and fidelity of terrestrial paleoclimate records. Science Advances, v.3, n.9, 2017, p. 1-11. DOI: $10.1126 /$ sciadv. 1700683

FRIEDMAN, G. M. Distinction between dune, beach, and river sands from their textural characteristics. Journal of Sedimentary Petrology, v. 31, p. 514-529, 1961. DOI: 10.1306/74D70BCD2B21-11D7-8648000102C1865D

FRIEDMAN, G. M. Dynamic processes and statistical parameters compared for size frequency distribution of beach and river sands. Journal of Sedimentary Petrology, v. 37, p. 327-354, 1967. DOI: 10.1306/74D716CC-2B21-11D7$8648000102 \mathrm{C} 1865 \mathrm{D}$

FRIEND, P.F. Towards the field classification of alluvial architecture or sequence. In: COLLINSSON, J.D.; LEWIN, J. (Ed.). Modern and ancient fluvial systems, v. 6. International Association of Sedimentologists, Special Publication, 1983, p. 345-354.

GIBLING, M.R. Width and thickness of fluvial channel bodies and valley fills in the geological record: a literature compilation and classification. Journal of Sedimentary Research, v. 76, 2006, p. 731-770. DOI: 10.2110/jsr.2006.060

GÓES, L. M. Geocronologia das coberturas superficiais nos baixos terraços fluviais e aluviões recentes no médio curso da bacia hidrográfica do rio Itapicuru (Bahia-Brasil). 125 p. Tese (Doutorado em Geografia) - Instituto de Geociências, Universidade Estadual de Campinas, Campinas 2019.

GOUDIE, A. Arid and semi-arid geomorphology. New York: Cambridge University Press, 2013. 454 p.

GRAF, W.L. Fluvial processes in Dryland Rivers. Berlin: Spring-Verlag, 1988. 346 p.

GUSTAVSSON, M.; KOLSTRUP, E.; SEIJMONSBERGEN, A.C. A new symbol-and-GIS- based detailed geomorphological mapping system: renewal of a scientific discipline for understanding landscape development. Geomorphology, 77, 2006, 90-111 p. DOI: 10.1016/j.geomorph.2006.01.026

INSTITUTO BRASILEIRO DE GEOGRAFIA E ESTATISTICA (IBGE). Manual Técnico de Geomorfologia. Rio de Janeiro: IBGE, Coordenação de Recursos Naturais e Estudos Ambientais. 2. ed., 2009.

LIMA, K.C. O Holoceno Superior na bacia do rio Itapicuru (Bahia/Brasil): proposição de cenário para o baixo curso e planície costeira. 127 p. Tese (Doutorado em Geografia) Instituto de Geociências, Universidade Estadual de Campinas, Campinas 2017.

LYRA, L.H.B. Dinâmica geomorfológica das ilhas do 
Massangano e Rodeadouro no alto submédio São Francisco. 251 p. Tese (Doutorado em Geografia), Universidade Federal de Sergipe, Aracaju, 2016.

MANN, M.E.; ZHANG, Z.; RUTHERFORD, S.; BRADLEY, R.S.; HUGHES, M.K.; SHINDELL, D.; AMMANN, C.; FALUVEGI, G.; NI, F. Global Signatures and Dynamical Origins of the Little Ice Age and Medieval Climate Anomaly. Science, v. 326, p. 1256-1260, 2009. DOI: 10.1126/science. 1177303

MATMON, A.; ELFASSI, S.; HIDY, A.; GELLER, Y.; PORAT, N.; ASTER Team. Controls on aggradation and incision in the NE Negev, Israel, since the middle Pleistocene. Geomorphology, 261, 2016. 132-146 p. DOI: 10.1016/j.geomorph.2016.02.020

MIALL, A. D. The geology of fluvial deposits - Sedimentary facies, basin analysis, and petroleum geology. Berlim: SpringerVerlag, 1996.

MIALL, A. D. Principles of sedimentary basin analysis. Berlim: Springer-Verlag, 2011, 3 ed.

MURRAY, A.S.; ROBERTS, R.G. Determining the burial of single grains of quartz using optical dating. Earth and Planetary Science Letters, 152, p. 163-180, 1998. DOI: 10.1016/S0012$821 \mathrm{X}(97) 00150-7$

MURRAY, A.S.; WINTLE, A.G. Luminescence dating of quartz using an improved single-aliquot regenerative-dose protocol. Radiations Measurements, 32, p. 57-73, 2000. DOI: 10.1016/ S1350-4487(99)00253-X

MUTZENBERG, D. S. Gênese e ocupação pré-histórica do Sítio Arqueológico Pedra do Alexandre: uma abordagem a partir da caracterização paleoambiental do Vale do Rio Carnaúba/RN. 142 p. Dissertação (Mestrado em Arqueologia) - Centro de Filosofia e Ciências Humanas, Universidade Federal de Pernambuco, Recife, PE, 2007.

NORTH, C.P.; TAYLOR, K.S. Ephemeral-Fluvial Deposits: Integrated Outcrop and Simulation Studies Reveal Complexity. AAPG Bulletin, v. 80, 6, p. 811-830, 1996.

NOVELLO, V.F.; CRUZ, F.W.; KARMANN, I.; BURNS, S.J.; STRIKIS, N.M.; VUILLE, M.; CHENG, H.; EDWARDS, R.L.; SANTOS, R.V.; FRIGO, E.; BARRETO, E.A.S. Multidecadal climate variability in Brazil's Nordeste during the last 3000 years based on speleothem isotope records. Geophysical Research Letters, v. 39, 1-6 p, 2012. DOI: 10.1029/2012GL053936

PETTIJOHN, F.J.; POTTER, P.E.; SIEVER, R. Sand and Sandstone. New York: Springer-Verlag, 1987.

PORAT, N.; AMIT, R.; ENZEL, Y.; ZILBERMAN, E.; AVNI, Y.; GINAT, H.; GLUCK, D. Abandonment ages of alluvial landforms in the hyperarid Negev determined by luminescence dating. Journal of Arid Environments, 74, p. 861-869, 2010. DOI: 10.1016/j.jaridenv.2009.10.018

REID, I.; FROSTICK, L.E. Channel form, flows and sediments in deserts. In: DAVID, S.G (Ed.). Arid Zone Geomorphology. 3. ed. Chichester: John Willey and Sons, 2011. p. 301-332.

SALLUN, A. E. M.; SUGUIO, K.; TATUMI, S. H.; YEE, M.; SANTOS, J.; BARRETO, A. M. F. Datação absoluta de depósitos quaternários brasileiros por luminescência. Revista Brasileira de Geociências, v. 37, n. 2, 2007, p. 402-413.

SAMPAIO, F. J. Geologia, geocronologia e paleoclima do quaternário continental da região sul da Chapada Diamantina - Bahia. 2013. 259 p. Tese (Doutorado em Geologia) - Instituto de Geociências, Universidade Federal da Bahia, Salvador, BA, 2013.

SANTOS, L.A. Geomorfologia e Quaternário do rio VazaBarris, Nordeste, Brasil. 2015. 79 p. Dissertação (Mestrado em Geociências) - Instituto de Geociências e Ciências Exatas, Universidade Estadual Paulista "Júlio de Mesquita Filho", Rio Claro, SP, 2015.

SCHUMM, S.A. Evolution and response of the fluvial system, sedimentologic implications. SEPM, special publication, 31, p. 19-29, 1981.

SILVA, T.C. Contribuição da geomorfologia ao estudo dos ambientes da caatinga. Simpósio sobre a caatinga e sua exploração racional. Anais... Feira de Santana, 1986. p. 49-71.

STOKES, S. Luminescence dating applications in geomorphological research. Geomorphology, 29, 1999, p. 153-171. DOI: 10.1016/S0169-555X(99)00012-4

SUGUIO, K. Geologia do quaternário e mudanças ambientais. São Paulo: Oficina de Textos, 2010.

SUPERINTENDÊNCIA DE ESTUDOS ECONÔMICOS E SOCIAIS DA BAHIA (SEI). Balanço hídrico do estado da Bahia. Salvador: SEI, 1999.

TAVARES, B.A.C. A participação da morfoestrutura na gênese da compartimentação geomorfológica do gráben do Cariatá, Paraíba. 2015. 137 p. Dissertação (Mestrado em Geografia) - Centro de Filosofia e Ciências Humanas, Universidade Federal de Pernambuco, Recife, PE, 2010.

THORNES, J. B. Catchment and channel hydrology. In ABRAHAMS, A. D.; PARSONS, A.J. (Ed.) Geomorphology of desert environments. 2 ed. London: Chapman and Hall, 2009, p. 257-287. 
TOOTH, S. Luminescence, Geomorphological Processes. In: RINCK, W.J.; THOMPSON, J.W. (Ed.) Encyclopedia of Scientific Dating Methods. New York: Springer, 2015, p. 470475.

TRICART, J. Pinciples et méthodes de la géomorphologie. Paris: Masson, 1965. 496 p.

VERSTAPPEN, H.T.; ZUIDAM, R.A.V. ITC System of geomorphological survey. 3. ed., Enschede: ITC, 1975, Vol. VII. 52 p.

VILES, H.A.; GOUDIE, A.S. Interannual, decadal and multidecadal scale climatic variability and geomorphology. Earth-Science Reviews, 61, 2003. p. 105-131. DOI: 10.1016/ S0012-8252(02)00113-7
WALLINGA, J. Optically stimulated luminescence dating of fluvial deposits: a review. Boreas, v. 31, 2002, p. 303-322. DOI: 10.1111/j.1502-3885.2002.tb01076.x

WINTLE, A. G.; MURRAY, A. S.; A review of quartz optically stimulated luminescence characteristics and their relevance in single-aliquot regeneration dating protocols. Radiations Measurements, 41, p. 369-391, 2006. DOI: 10.1016/j. radmeas.2005.11.001

YAIR, A.; KOSSOVSKY, A. Climate and surface properties: hydrological response of small arid and semi-arid watersheds. Geomorphology, 42, 2002, p. 43-57. DOI: 10.1016/S0169$555 \mathrm{X}(01) 00072-1$ 
Anexo 1:

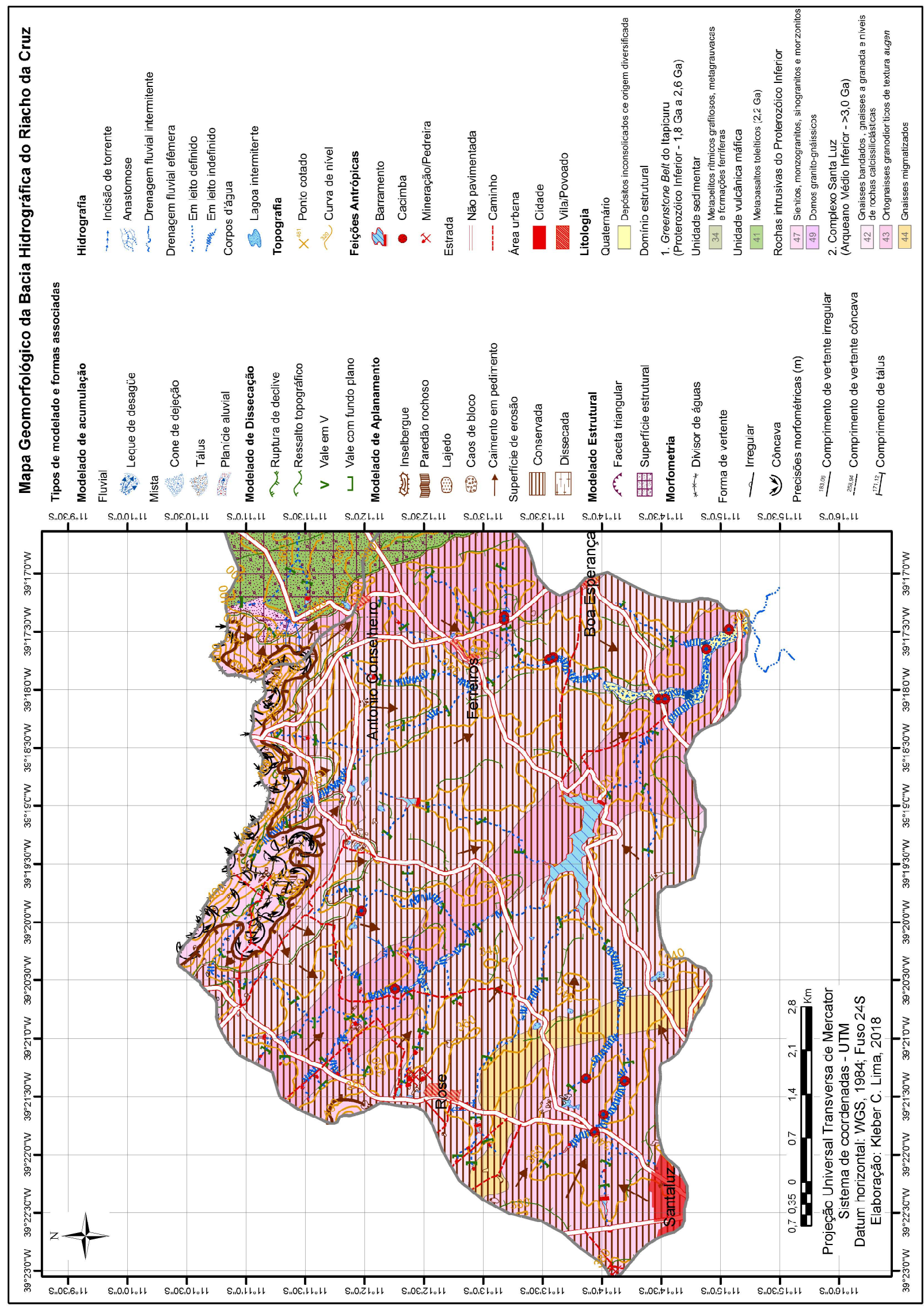




\section{Anexo 2:}

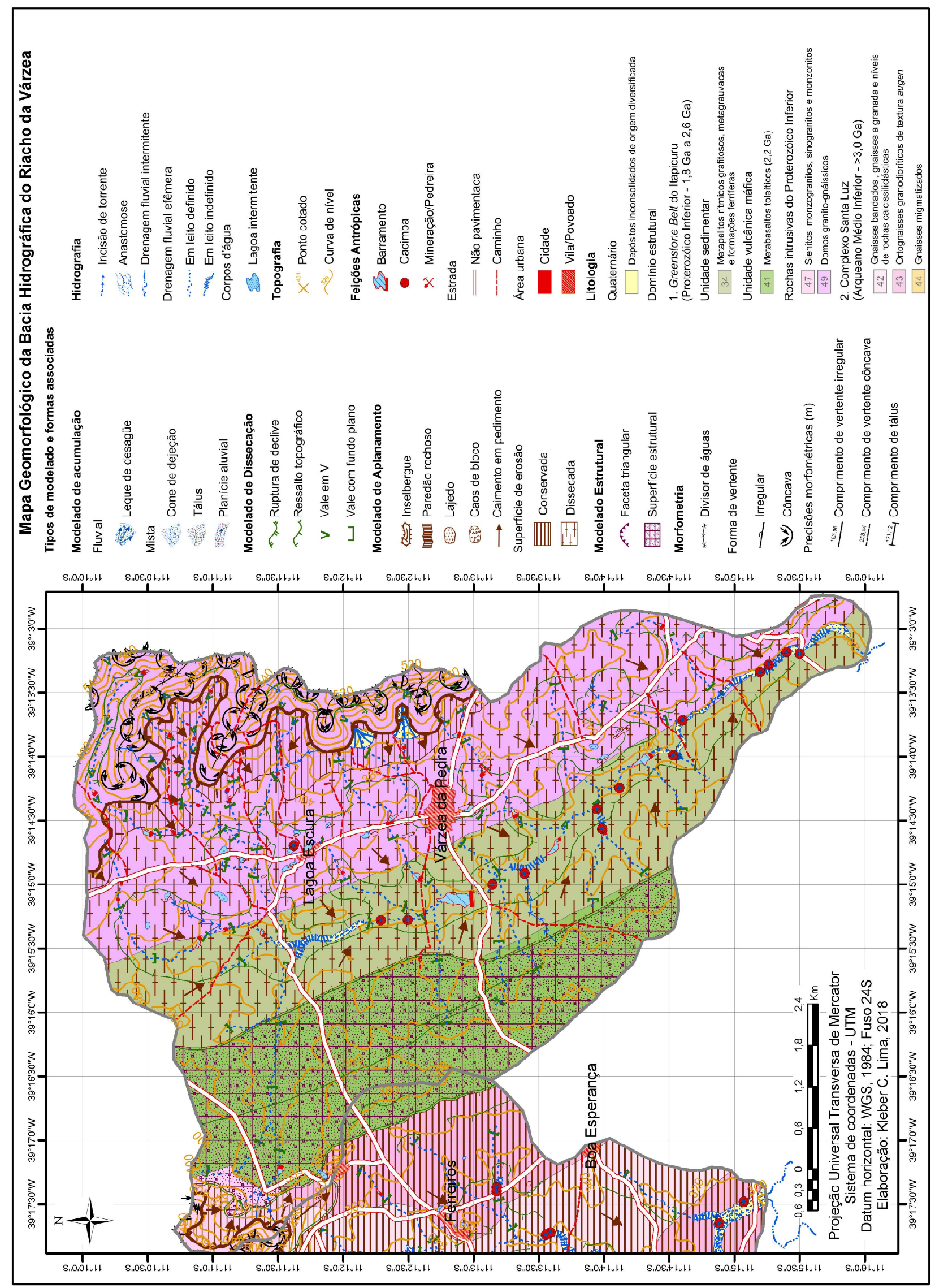

